OPEN ACCESS

Edited by:

Cecilia Poderoso,

University of Buenos Aires, Argentina

Reviewed by:

Amandine Grimm,

University of Basel, Switzerland

Tito Cali,

University of Padova, Italy

Charles Affourtit,

University of Plymouth,

United Kingdom

*Correspondence:

Celia Quijano

celiq@fmed.edu.uy;

celia.quijano@gmail.com

Specialty section

This article was submitted to

Cellular Endocrinology,

a section of the journal

Frontiers in Endocrinology

Received: 17 February 2020

Accepted: 27 April 2020

Published: 22 May 2020

Citation:

Martínez J, Marmisolle I, Tarallo D and Quijano C (2020) Mitochondrial Bioenergetics and Dynamics in

Secretion Processes.

Front. Endocrinol. 11:319.

doi: 10.3389/fendo.2020.00319

\section{Mitochondrial Bioenergetics and Dynamics in Secretion Processes}

\author{
Jennyfer Martínez, Inés Marmisolle, Doménica Tarallo and Celia Quijano* \\ Departamento de Bioquímica, Centro de Investigaciones Biomédicas (CEINBIO), Facultad de Medicina, Universidad de la \\ República, Montevideo, Uruguay
}

Secretion is an energy consuming process that plays a relevant role in cell communication and adaptation to the environment. Among others, endocrine cells producing hormones, immune cells producing cytokines or antibodies, neurons releasing neurotransmitters at synapsis, and more recently acknowledged, senescent cells synthesizing and secreting multiple cytokines, growth factors and proteases, require energy to successfully accomplish the different stages of the secretion process. Calcium ions $\left(\mathrm{Ca}^{2+}\right)$ act as second messengers regulating secretion in many of these cases. In this setting, mitochondria appear as key players providing ATP by oxidative phosphorylation, buffering $\mathrm{Ca}^{2+}$ concentrations and acting as structural platforms. These tasks also require the concerted actions of the mitochondrial dynamics machinery. These proteins mediate mitochondrial fusion and fission, and are also required for transport and tethering of mitochondria to cellular organelles where the different steps of the secretion process take place. Herein we present a brief overview of mitochondrial energy metabolism, mitochondrial dynamics, and the different steps of the secretion processes, along with evidence of the interaction between these pathways. We also analyze the role of mitochondria in secretion by different cell types in physiological and pathological settings.

Keywords: mitochondria, secretion, bioenergetics, ATP, calcium, dynamics, endoplasmic reticulum, exocytosis

\section{INTRODUCTION}

About $20 \%$ of the proteins synthesized by eukaryotic cells are secreted to the extracellular space either as soluble or membrane bound proteins (1). The secretory pathway in eukaryotic cells is responsible for biogenesis and proper distribution of a wide range of extracellular proteins, as well as complex carbohydrates and lipids. This pathway is highly dynamic and responsive to specific cellular demands and stimuli (2). Eukaryotic cells also secrete many amino acids and amino acid derivatives, such as neurotransmitters, that play key roles in intercellular communication (3).

As many other complex cellular processes secretion of proteins consumes energy, therefore requires the support of functional mitochondria. In the conventional pathway proteins are transported into the endoplasmic reticulum (ER), and folding and quality control of proteins in the ER (4-8) consumes ATP. Likewise the assembly, transport and fusion of the vesicles carrying proteins from the ER to the Golgi and to the plasma membrane requires the hydrolysis of ATP, as well as GTP $(2,9,10)$. Besides, several steps in the secretion process depend on calcium ion $\left(\mathrm{Ca}^{2+}\right)$ as a cofactor or signaling molecule $(11,12)$. Calcium pumps are required to maintain the appropriate concentrations of $\mathrm{Ca}^{2+}$ inside the ER and near the sites of exocytosis, and mitochondria play a relevant role providing energy to transport $\mathrm{Ca}^{2+}$ against its concentration gradient $(13,14)$. 
Mitochondria also modulate $\mathrm{Ca}^{2+}$ concentrations in the cytosol, sequestering the ion in the mitochondrial matrix $(14,15)$. Secretion of proteins by unconventional pathways also depends on mitochondria, not only as a source of ATP, but also of activation signals such as mitochondrial reactive oxygen species (ROS) and oxidized mtDNA $(16,17)$, as well as a structural platform for the assembly of inflammasomes $(17,18)$.

Work by others and us shows that impairment of mitochondrial catabolism and dynamics affects the secretion processes $(6,7,19-26)$ and can underlie pathology in endocrine and neurodegenerative diseases (27-30). Relevant roles for mitochondria in protein secretion by immune and senescent cells have been recently described as well (19-21, 24-26, 31), underscoring the relevance of these interactions. This prompted us to explore the existing literature on mitochondrial interactions with the secretion machinery.

While extensive literature can be found regarding both secretion and mitochondrial bioenergetics and dynamics, the connection between these processes and the organelles involved are still largely unexplored. In this manuscript secretion pathways, mitochondrial metabolism and dynamics per se have not been extensively reviewed. We have relied on reviews by others to present an overview, and centered our efforts in exploring the requirement for mitochondrial ATP and fusion and fission proteins to sustain secretion in metazoans, excluding the events linked to ER stress. We expand on three main roles of mitochondria: (1) providing ATP for multiple steps of the secretion process; (2) buffering $\mathrm{Ca}^{2+}$ concentrations; (3) providing signals and structural scaffold for the activation of the inflammasome (Figure 1).

\section{OVERVIEW OF THE SECRETION PATHWAYS AND THEIR ENERGY DEMANDS}

Secreted proteins can reach the extracellular media through the conventional (classic) pathway or through unconventional pathways (32). In the conventional pathway proteins are transported into the ER, either cotranslationally or

\footnotetext{
Abbreviations: ARF, ADP-ribosylation factor; $\mathrm{BiP}$, ER chaperone $\mathrm{BiP} ; \mathrm{Ca}^{2+}$, calcium; COPI, coat protein complex I; COPII, coat protein complex II; DRP1, GTPase dynamin related protein 1; EDEM, ER degradation-enhancing alphamannosidase-like proteins; ER, endoplasmic reticulum; ERAD, endoplasmic reticulum- associated degradation; ERES, ER exit sites; ERGIC, ER-Golgi intermediate compartment; ERMCs, ER-mitochondrial contact sites; ETC, electron transport chain; FIS1, fission 1 protein; GRP, glucose regulated protein; GSIS, glucose-stimulated insulin secretion; GT, UDP-glucose:glycoprotein glucosyltransferase; IL-1 $\beta$, interleukin- $1 \beta$; IMM, inner mitochondrial membrane; IP3, inositol-1,4,5-trisphosphate; IP3R, inositol-1,4,5-trisphosphate- sensitive channel or receptor; MCU, mitochondrial calcium uniporter; MICOS, mitochondrial contact site and cristae-organizing system; MICU, MCU regulator and mitochondrial calcium uptake; MFN1, mitofusin 1; MFN2, mitofusin 2; MIRO, mitochondrial Rho GTPase; NLRP3, Nod-like receptor family, pyrin domain containing 3; OMM, outer mitochondrial membrane; OPA1, optic atrophy protein 1; ROS, reactive oxygen species; SAR1, secretion associated Ras related 1 GTPAse; SASP, senescence-associated secretory phenotype; SERCA, sarcoplasmic/endoplasmic reticulum calcium ATPase; SRP, signal recognition particle; TNF, tumor necrosis factor, VDAC, voltage-dependent anion channel.
}

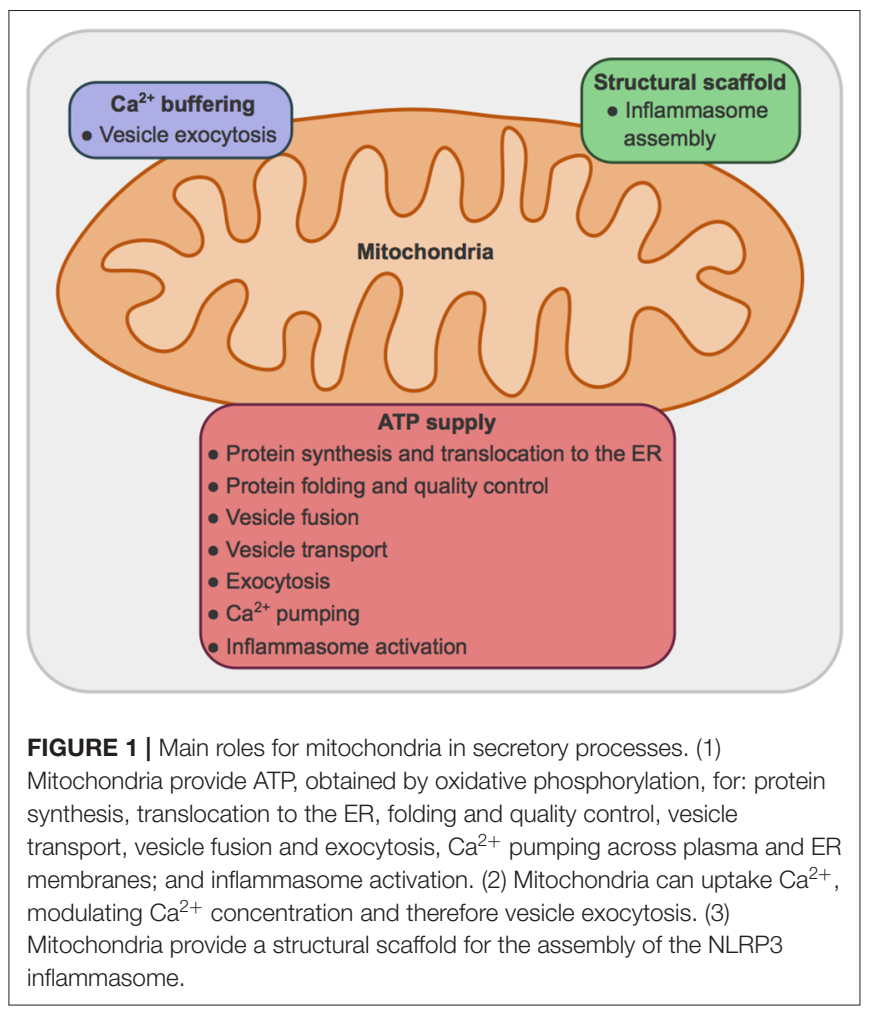

postranslationally; then travel from the ER to the Golgi complex, from which they then migrate to the trans-Golgi network and finally to the plasma membrane $(33,34)$. Transport from one compartment to another takes place by sequential budding and fusion of vesicles (35) and the microtubule and actin cytoskeleton plays a relevant role in vesicle transport $(33,36)$ (Figure 2). Unconventional secretion pathways, on the other hand, include proteins that do not present a leader sequence and proteins that by-pass the Golgi apparatus while traveling to the plasma membrane (32).

\section{Conventional Pathway for Protein Secretion}

Most of the secreted proteins in the conventional pathway are translocated to the rough ER during translation by the ribosome (37). Proteins are targeted to the ER by a hydrophobic signal peptide located in the N-terminus, which is later cleaved by a signal peptidase present in the ER lumen. The signal peptide is recognized by the signal recognition particle (SRP) that then binds to the SRP receptor (SR) $(33,38)$. Both SRP and SR are GTPases and the docking and release of SRP at the ER membrane requires GTP $(37,39)$. Docking is followed by the translocation of the nascent protein to the ER lumen through the translocon, a pore that in mammals is composed of Sec61 proteins, and associated proteins including BiP, Sec63, Sec62, translocating-chain-associated protein (TRAM), transloconassociated protein (TRAP), and ribosome-associated membrane protein (RAMP) $(37,40,41)$. BiP plays a dual role during protein translocation, it seals de pore and provides the driving force to 


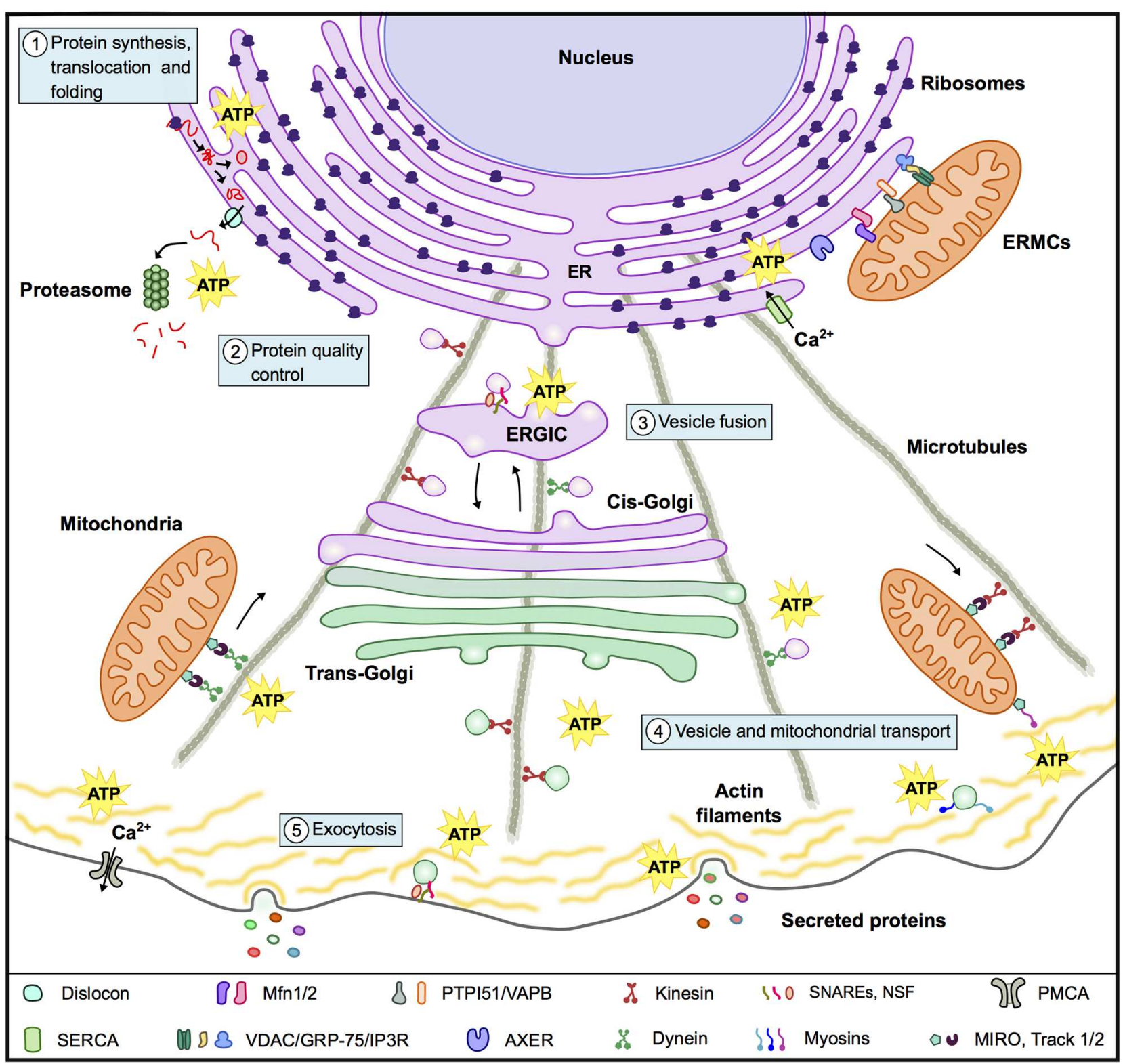

FIGURE 2 | Mitochondria and the conventional secretion machinery. To support the energy requirements of the secretion process mitochondria interact with organelles and components of the cytoskeleton and supply ATP for: (1) Protein synthesis, translocation to the ER and folding. (2) Protein quality control in particular for the energy consuming ERAD. (3) Vesicle fusion with target membranes in the ER, ERGIC, Golgi, and plasma membrane. (4) Vesicle and mitochondrial transport along microtubules and actin filaments. (5) Exocytosis. In the panel below the figure are a series of molecules and complexes that play relevant roles in these events.

transfer of the nascent protein into the ER $(4,40)$. This protein is an ATP-dependent chaperone that belongs to the heat shock protein 70 (Hsp70) family. During protein translocation BiP interacts with co-chaperones Sec63 and RAMP, these ER-resident J-domain proteins (ERdjs) stimulate BiP binding to the nascent protein and ribosomes as well as ATP hydrolysis $(4,41)$. BiP also interacts with the nucleotide exchange factors GRP170 and Sil1 that promote the exchange of ADP for ATP $(41,42)$. Though ATP hydrolysis by BiP is the main driving force for translocation, GTP hydrolysis during the elongation stage of protein synthesis may also contribute to the process $(4,40)$ (Table 1 and Figure 2).

In the ER, the oligosaccharyl transferase complex (OGT) catalyzes the transfer of the oligosaccharide $\left(\mathrm{Glc}_{3} \mathrm{Man}_{9} \mathrm{GlcNAc}_{2}\right)$ from dolichol phosphate to an asparagine residue in the protein $(52,53)$. Exoglucosidases I and II then catalyze the removal of two terminal glucose moieties producing a monoglucosylated structure $\left(\mathrm{Glc}_{1} \mathrm{Man}_{9} \mathrm{GlcNAc}_{2}\right)$ that is recognized and bound by lectin chaperones calnexin and calreticulin. These chaperones, in collaboration with BiP, GRP-94 and protein disulfide 
TABLE 1 | The conventional pathway for protein secretion and its energy requirements.

\begin{tabular}{|c|c|c|}
\hline Process & Associated proteins & References \\
\hline $\begin{array}{l}\text { Protein } \\
\text { synthesis }\end{array}$ & $\begin{array}{l}\text { Aminoacyl-tRNA synthetases, initiation } \\
\text { factors, elongation factors, termination } \\
\text { factors, ribosomes }\end{array}$ & $(43)$ \\
\hline $\begin{array}{l}\text { Protein } \\
\text { translocation }\end{array}$ & $\begin{array}{l}\text { SRP, SRP receptor, SEC61, SEC62, } \\
\text { SEC63, BiP, GRP170, SIL1, TRAM, TRAP }\end{array}$ & $(4,40)$ \\
\hline Protein folding & $\begin{array}{l}\text { OGT, exoglucosidases I and II, calnexin, } \\
\text { calreticulin, GT, PDIA3, BiP, GRP-94 }\end{array}$ & $(41,44)$ \\
\hline $\begin{array}{l}\text { Protein quality } \\
\text { control }\end{array}$ & 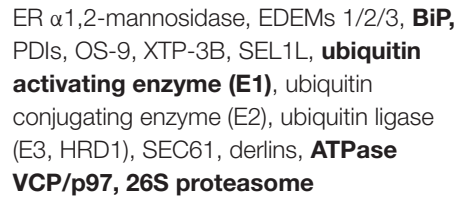 & $(41,45,46)$ \\
\hline $\begin{array}{l}\text { COPII and } \\
\text { COPI } \\
\text { vesicle } \\
\text { assembly }\end{array}$ & $\begin{array}{l}\text { SAR1, ARF, SEC12, SEC16, SEC23, } \\
\text { SEC24, SEC13, SEC31, COPI subunits, } \\
\text { GEFs, GAPs }\end{array}$ & $(47,48)$ \\
\hline Vesicle fusion & $\begin{array}{l}\text { Receptors, Rab GTPases, Rab effectors } \\
\text { SNARE proteins, SM proteins, SNAP, NSF }\end{array}$ & $(2)$ \\
\hline $\begin{array}{l}\text { Vesicle } \\
\text { transport }\end{array}$ & Kinesin, dynein, myosins & $(9,49)$ \\
\hline Exocytosis & $\begin{array}{l}\text { Rab GTPases, Rab effectors SNARE } \\
\text { proteins, SM proteins, SNAP, NSF, actin, } \\
\text { myosins }\end{array}$ & $(50,51)$ \\
\hline
\end{tabular}

Relevant molecules involved in the different steps of the conventional secretion pathway are listed. Proteins that catalyze ATP hydrolysis are highlighted in bold letters.

isomerase A3 (PDIA3, Erp57), help the protein acquire its native conformation $(8,38)$. Removal of the remaining glucose moiety by exoglucosidase II prevents further binding of the glycoprotein to calnexin and calreticulin, allowing it exit to the ER. However, if the native structure is not achieved the protein undergoes reglucosylation catalyzed by UDPglucose:glycoprotein glucosyltransferase (GT), an enzyme that preferentially acts on incompletely folded glycoproteins. Thereby favoring a new cycle of interactions with calnexin and calreticulin and the other components of the folding machinery $(8,54,55)$. Protein folding requires ATP, since chaperones BiP and GRP94 hydrolyze ATP during their catalytic cycles $(41,44)$. Besides, calnexin and calreticulin bind ATP though they do not hydrolize it (56). Calnexin and calreticulin also bind $\mathrm{Ca}^{2+}$, therefore $\mathrm{Ca}^{2+}$ homeostasis must be maintained in the ER lumen (56). The sarcoplasmic/endoplasmic reticulum calcium ATPase (SERCA) is responsible of coupling ATP hydrolysis to $\mathrm{Ca}^{2+}$ transport from the cytosol to the ER $(4,57)$ (Figure 2).

In the ER proteins undergo quality control pathways for the detection, remotion, and degradation of misfolded proteins that did not attain their native structures. Degradation by the proteasome takes place in the cytosol in a pathway known as ER-associated degradation (ERAD) $(8,45)$. The first step in this pathway is the recognition of the misfolded protein and several luminal and cytoplamatic factors are involved in this process (46). Among them we find ER mannosidases (ER $\alpha 1,2$ mannosidase and EDEMs, 1, 2, and 3) that trim the mannose residues from glycoproteins, preventing glucosylation by GT and therefore withdrawing the protein from the quality control cycle $(8,58)$. Mannose trimmed glycoproteins bind OS-9 and XTP-3B and associate with SEL1L that channels the misfolded protein to the dislocon where proteins are retrotranslocated to the cytosol (45). Though the dislocon is not well-characterized it is thought to include Sec61, the E3 ligase HRD1, Derlins 1-3, and ATPase $\mathrm{VCP} / \mathrm{p} 97$, which converts the energy released by ATP hydrolysis into mechanical force for the extraction process $(4,45)$. BiP and PDIs (ERdj5 and ERp90), also play a role, at this stage, binding and oxidizing the proteins to be transported $(41,59)$. In the cytosol, ubiquitin activating enzymes (E1), conjugating enzymes (E2), and E3 ligases (primarly HRD1 and AMFR) transfer ubiquitin to the protein in an ATP-dependent process (46). Finally, ubiquitinated proteins are degraded by the $26 \mathrm{~S}$ proteasome in a pathway that also consumes ATP $(45,46)$. Overall the ERAD is an extremely costly process that consumes ATP during the extraction, ubiquitination and degradation of misfolded proteins $(4,41,45)$ (Table 1 and Figure 2).

Secretory proteins that achieve the correct folded and assembled conformation are then transported from the ER to the Golgi complex in coat protein complex II (COPII) carrier vesicles (47). Vesicles for anterograde (forward) transport are formed in ER exit sites (ERES) and key proteins involved in their assembly include SEC12, SEC16, secretion-associated Rasrelated 1 (SAR1) GTPase and the two major coat subunits SEC23- SEC24 and SEC13- SEC31 $(47,60)$. Proteins enter the vesicles by diffusion (bulk-flow), or undergo selective uptake (cargo capture) by SEC24, and other receptors (2, 48, 61). Upon leaving the ERES COPII vesicles shed their SEC13- SEC31 coats in a process that involves the hydrolysis of GTP bound to SAR1 (62), and fuse with one another or with the ER-Golgi intermediate compartments (ERGIC) $(2,47)$. Rab-family small GTPases and Rab effectors are involved in vesicle tethering to the membranes. After tethering vesicles fuse with the acceptor compartment delivering the cargo to the Golgi $(2,48)$. Retrieval of misplaced ER luminal proteins from the ERGIC or from the Golgi is achieved by retrograde transport in coat protein complex I (COPI) carrier vesicles. Formation of COPI vesicles involves the ADP-ribosylation factor 1 (ARF) GTPase, that recruits the coatomer subunits to the membrane (48). Vesicle formation, coat shedding and tethering to target membranes are energy consuming processes that consume GTP (2). SAR1 and ARF GTPases switch between inactive GDP-bound and active GTP-bound forms. Guanine nucleotide exchange factors (GEFs) catalyze the release of GDP (allowing the union of a new GTP molecule); while GTPase-activating proteins (GAPs) promote the hydrolysis of bound GTP, regulating enzyme activity and therefore vesicle trafficking $(2,63)$ (Table 1).

From the cis-Golgi compartment proteins are transported via cisternal maturation to the trans-Golgi network (48), where proteins to be secreted are sorted in secretory vesicles and delivered to the plasma membrane, to the endosomal system or to immature secretory granules $(33,48)$. Motor proteins, kinesin, and dynein transport the cargo vesicles along microtubules. Kinesins transport secretory vesicles from the organelles where they arise to the cortical region, while dynein mediates their 
transport in the opposite direction $(49,64)$. Myosin V and II are responsible for the movement of vesicles along actin filaments in the cortical area $(49,50)$. The cortical actin network, at the cell borders, acts as a diffusion barrier that prevents the access of granules to secretory sites until the arrival of the triggering stimuli (50). Motor proteins, kinesin, dynein and myosin use the energy released during ATP hydrolysis to move vesicles along microtubules and actin filaments (9) (Table $\mathbf{1}$ and Figure 2).

Upon arrival to the plasma membrane secretory proteins are released to the extracellular space by exocytosis. Constitutive exocytosis occurs in all cell types to release extracellular proteins and maintain plasma membrane homeostasis and cell polarity. While regulated exocytosis occurs in specialized secretory cells and is triggered by secretion signals (13), such as increases in $\mathrm{Ca}^{2+}$ concentrations (65). Calcium ions bind sensor molecules and promote the fusion of vesicles with the plasma membrane (65). Upon the arrival of the secretion stimuli myosin II drives the movement of vesicles to the fusion sites where they dock to the plasma membrane (66). SNARE complexes (formed by syntaxin, SNP-25, and VAMP), and SM proteins (such as Munc18-1), are in charge of the fusion of vesicles with the plasma membrane $(10,13,51)$, while the actin and myosin network contributes to the release of vesicle contents in an ATPdependent manner $(50,66,67)$. Fusion of vesicles with target membranes also consumes ATP. SNARE proteins localized in vesicles and target membranes interact forming a complex that pulls the two membranes together, exerting the force required for fusion. The dissociation of the SNARE complex involves soluble NSF attachment protein (SNAP) and the ATPase Nethylmaleimide-sensitive fusion protein (NSF) that hydrolyses $\operatorname{ATP}(10,51)$ (Table 1 and Figure 2).

Overall the concerted action of many cellular components is required to ensure the selective and efficient secretion of proteins. Many of these steps require energy and mitochondria play a relevant role, fulfilling the ATP requirements of the pathway (Figures 1, 2). Besides, mitochondria help to modulate the intracellular concentrations of $\mathrm{Ca}^{2+}(13,14)$, an essential cofactor in the folding process and a potent trigger of exocytosis (65) (Figure 1).

\section{Unconventional Pathways for Protein Secretion}

Though the conventional protein secretion pathway was considered for a long time as the only mechanism for protein secretion, we now know that many proteins use alternative pathways. These include the secretion of cytosolic proteins that do not have a signal peptide (leaderless proteins) or a transmembrane domain; and proteins that contain a signal peptide or a transmembrane domain and enter the ER but are not transferred to the Golgi complex (68).

Proteins without a leader sequence are secreted along three different pathways: Type I pathways involve the translocation from the cytoplasm to the extracellular space through a pore in the plasma membrane. In Type II secretion processes the ATPbinding cassette transporter is responsible for the secretion of the protein present in the cytoplasm while in Type III secretion the proteins use autophagosomes and endosomes to reach the extracellular space. The Golgi-bypassing route is also known as Type IV secretion pathway (68). Some proteins are constitutively secreted through unconventional pathways, however these pathways are usually induced in stressful conditions, such as nutrient starvation, inflammation, and mechanical or ER stress $(32,68)$.

One of the most studied proteins secreted by the unconventional pathways is interleukin-1 $\beta$ (IL-1 $\beta)(68,69)$. During inflammation IL- $1 \beta$ is produced as an immature and inactive form that is cleaved by caspase 1 upon recruitment and activation by the Nod-like receptor family pyrin domain containing 3 (NLRP3) inflammasome (70), in a process that will be discussed below in detail. The assembly and activation of the complex is an energetically costly event that requires the hydrolysis of ATP by NLRP3 (71). The posterior secretion of mature IL-1 $\beta$ involves the formation of a pore that increases the permeability of the plasma membrane (69) or occurs through the autophagosome/endosmal pathway (68).

\section{Secretion Pathway of Neurotransmitters}

Many neurotransmitter molecules are amino acids or amino acid derivatives and their secretion occurs through exocytosis. The pathway starts with the synthesis of the neurotransmitters by enzymes, followed by their loading into of synaptic vesicles. The loading process involves transporters in the vesicle membrane and happens at the expense of an electrochemical proton gradient, generated by the vacuolar $\mathrm{H}^{+}$-ATPase. This pump uses the energy released by ATP hydrolysis to transport protons into the vesicle lumen (72). Loaded vesicles can then be sequestered in a reserve pool or travel to specialized release sites, known as active zones, at the presynaptic terminal where vesicles become docked at the plasma membrane. Increases in $\mathrm{Ca}^{2+}$ concentrations promote the fusion of the vesicle with the plasma membrane and discharge their content into the synaptic cleft (73). Calcium sensing, vesicle docking and exocytosis follow the same steps described for the conventional secretion pathway of proteins (51). These steps are followed by the recovery of the synaptic vesicle membranes that are recycled for refilling in preparation for the next cycle of exocytosis (74).

\section{OVERVIEW OF MITOCHONDRIAL STRUCTURE, FUNCTION AND DYNAMICS}

\section{Mitochondrial Bioenergetics}

Mitochondria are cell organelles defined by a double membrane, the outer mitochondrial membrane (OMM) and the inner mitochondrial membrane (IMM). The OMM separates the mitochondria from the cytosol, however the voltage-dependent anion channel (VDAC or porin) allows the passage of metabolites and ions. In the OMM are also located proteins involved in apoptosis, mitochondrial dynamics, and tethering to other organelles. In the IMM, two functional and structurally different regions are described: the inner boundary membrane and the cristae, where electron transport and ATP synthesis take place in a process known as oxidative phosphorylation (75). In the cristae we find the electron transport chain (ETC) 
complexes: NADH-ubiquinone oxidoreductase (complex I), succinate-ubiquinone oxidoreductase (complex II), ubiquinolcytochrome c oxidoreductase (complex III), and cytochrome c oxidase (complex IV), as well as the $\mathrm{F}_{\mathrm{o}} \mathrm{F}_{1}$-ATP synthase (ATP synthase or complex V) and two mobile electron carriers, ubiquinone and cytochrome $\mathrm{c}$ (75).

The ETC complexes are assembled forming supercomplexes that optimize electron transport and proton shuttling through the IMM $(76,77)$. ATP synthase localizes on the edges of cristae forming dimers, which optimize ATP production (78). At the cristae junctions we find the mitochondrial contact site and cristae-organizing system (MICOS), a large oligomeric complex that interacts with both the IMM and OMM (79). Cristae structure influences the ETC, complex and supercomplex formation, and can present different morphologies depending on the metabolic state of the cell (80).

Mitochondria are the main source of ATP in most cells, since many catabolic pathways converge in this organelle and result in the production of ATP by oxidative phosphorylation. The catabolism of metabolites such as glucose, proteins, and fatty acids produces acetyl-CoA, which is in turn oxidized in the tricarboxylic acid cycle generating the reduced electron donors nicotinamide adenine dinucleotide $(\mathrm{NADH})$ and flavin adenine dinucleotide $\left(\mathrm{FADH}_{2}\right)$. Electrons are then transferred to the ETC and flow through the complexes to molecular oxygen $\left(\mathrm{O}_{2}\right)$. This thermodynamically favorable electron transport releases energy, which is used to pump protons from the matrix to the intermembrane space, at complexes I, III, and IV, creating an electrochemical gradient (81). The energy released by the dissipation of the electrochemical proton gradient is then coupled to the synthesis ATP from ADP and Pi, catalyzed by ATP synthase $(82,83)$.

\section{Reactive Oxygen Species in Mitochondria}

Mitochondrial catabolism of nutrients and electron transport in the respiratory chain involves many redox reactions that have as by-products reactive oxygen species (ROS) (84). In particular, superoxide anion radical is formed by several flavoproteins and at complex I and III of the respiratory chain, and its dismutation gives rise to hydrogen peroxide (85). These mildly oxidant species can result in the formation of higher oxidant species such as peroxynitrite, formed in the reaction between superoxide and nitric oxide, oxo-metal complexes, nitrogen dioxide, and hydroxyl radical (86).

Under physiological conditions mitochondria produce controlled levels of oxidants, many of which participate in signaling processes. However, ROS formation can increase during cellular stress or in pathological conditions. Although mitochondrial oxidants can be detoxified by enzymatic and nonenzymatic antioxidants $(87,88)$, an imbalance in mitochondrial redox status may lead to mitochondrial damage $(84,89,90)$. In fact, oxidants impair the activity of enzymes of the tricarboxylic acid cycle, the ETC, and ATP synthase $(84,90)$.

\section{Mitochondrial Dynamics}

Mitochondrial dynamics consists of fusion and fission events driven mainly by dynamin-related GTPases (91). Optic atrophy protein 1 (OPA1) and mitofusins 1 and 2 (MFN1 and MFN2) are involved in mitochondrial fusion. The long OPA1 isoform is anchored to the inner membrane, where it promotes IMM fusion. The soluble and short OPA1 isoform, found in the intermembrane space, maintains mitochondrial cristae structure (92). MFN1 and MFN2 participate in tethering and fusion of the outer membranes of two different mitochondria through the formation of homo and heteroligomeric complexes $(93,94)$. Phospatidic acid, a fusogenic lipid formed in a reaction catalyzed by mitochondrial phospholipase $\mathrm{D}$, is also required for OMM fusion (95).

In turn, mitochondrial fission is carried out by the GTPase dynamin related protein 1 (DRP1), a cytosolic protein that is recruited to the OMM (96) by receptor proteins, such as mitochondria fission factor (97), mitochondrial dynamics protein of 49 and $51 \mathrm{kDa}$ (98) and fission 1 protein (FIS1) (99). DRP1 oligomerizes around mitochondria into a ringlike structure constricting the organelle (96). ER-mitochondrial contacts play a role in mitochondrial fission, determining the position of the fission events (100) and ER tubules wrap around mitochondria and constrict them (100). Components of the cytoskeleton such as actin, myosin II and septin 2 are required for mitochondrial fission (101-104), as well as the ER protein inverted formin 2 (105) and a mitochondrial Spire1 isoform (103). The latter two cooperate to induce localized actin polymerization at the constriction sites (103). Both fusion and fission are highly regulated processes, and changes in protein levels, GTPase activity and post-translational modifications of proteins involved in mitochondrial dynamics affect not only mitochondrial morphology but also cellular bioenergetics and homeostasis (106).

Multiple studies linking mitochondrial morphology and bioenergetics can be found in the literature (107-109). At the molecular level several reports support that MFN2 is required for correct mitochondrial function (110); since its silencing results in an impairment of oxidative phosphorylation, while overexpression enhances mitochondrial metabolism (19, 111113). Less evidence supports a role for MFN1. Although there are reports on MFN1 silencing decreasing mitochondrial respiration (114) this does not seem to be the case in all models (19). OPA1 deletion also affects mitochondrial membrane potential, respiration and cristae structure and reduces assembly, and stability of supercomplexes $(80,114-117)$.

In order to face increases in energy demands, such as those imposed by secretion, mitochondria also modify their cellular distribution. Motor proteins, kinesin, and dynein, transport mitochondria over long distances along microtubules toward the cell periphery or the cell center, respectively (49). While myosin 19, mediates short-range movement along the actin filaments near the cell periphery $(49,118)$. The mitochondrial Rho GTPase (MIRO) and the adaptor proteins trafficking kinesinbinding proteins 1 and 2 (TRAK1 and 2) support bidirectional mitochondrial movement along microtubules by binding kinesin and dynein (119-121) (Figure 2). MIRO proteins also engage myosin 19, linking mitochondria to actin filaments (122) and interact with components of the MICOS complex, linking the transport machinery to cristae organization and ensuring 
the appropriate provision of energy to the regions where mitochondria are delivered (123).

\section{ER-Mitochondria Contact Sites (ERMCs)}

Mitochondria can interact with several cellular compartments, including organelles involved in protein secretion such as the Golgi complex and ER (124-126). In particular, mitochondrial interactions with the ER have been extensively studied and many components and functions of the ER-mitochondrial contact sites (ERMCs) ${ }^{1}$ have been identified. ERMCs are crucial sites for the synthesis and exchange of lipids, $\mathrm{Ca}^{2+}$ transport, mitochondrial fission and inflammasome formation $(4,125,127)$.

Among the proteins found in ERMCs is MFN2, and though some controversy exists $(128,129)$, this protein is proposed to link the ER membrane to mitochondria through interactions with MFN1 and MFN2 in the OMM $(130,131)$. The mitochondrial proteins MITOL and mitostatin, as well as the ER protein presenilin 2 modulate these MFN2-dependent interactions between organelles (132-134). Other relevant proteins linking mitochondria to the ER are VDAC, the OMM chaperone GRP-75 and the inositol-1,4,5-trisphosphate-sensitive channel or receptor (IP3R) in the ER. Another tethering complex is formed between the ER protein vesicle-associated membrane protein- associated protein B (VAPB) and the OMM protein tyrosine phosphatase-interacting protein 51(PTPIP51) (135137) (Figure 2).

Physical tethering of mitochondria and the ER by mitofusins (130, 131), VDAC/IP3R/GRP-75 (14, 138), and VAPB/ PTPIP51 (135) is required for efficient transport of $\mathrm{Ca}^{2+}$ between organelles. Besides, several regulatory proteins modulate $\mathrm{Ca}^{2+}$ release from the ER and uptake by mitochondria, through interactions with IP3R or VDAC $(123,138,139)$. Of particular interest is the chaperone calnexin, whose translocation to different ER domains is regulated by palmitoylation of two conserved cysteine residues (140) and interaction with regulatory proteins (138). Calnexin migration to the ERMCs is required for $\mathrm{Ca}^{2+}$ transfer from the ER to the mitochondria (141).

Calcium ion leaves the ER through the I3PR and enters the mitochondria through VDAC and the mitochondrial calcium uniporter (MCU) complex present in the OMM and IMM, respectively $(14,138)$. The complex is formed by the MCU, a pore that allows the passage of the ions through the lipid membrane $(142,143)$, essential MCU regulator (ERMES) and mitochondrial calcium uptake 1 and 2 proteins (MICU1 and 2) that act as gatekeepers regulating $\mathrm{Ca}^{2+}$ uptake (144). Calcium entry to mitochondria occurs at the expense of the $\mathrm{H}^{+}$gradient in the IMM (144). In the matrix, $\mathrm{Ca}^{2+}$ activates several dehydrogenases (including enzymes of the tricarboxylic acid cycle) and ATP synthase enhancing oxygen consumption rate and ATP synthesis $(15,144)$. Thus, MERCs are extremely important for mitochondrial function. On the other hand $\mathrm{Ca}^{2+}$ uptake by mitochondria prevents or "buffers" the increase of $\mathrm{Ca}^{2+}$ concentrations near the mouth of the IP3R affecting its activity as we will describe in detail in the next section (14).

${ }^{1}$ ERMCs are also known as MERCs or mitochondria-associated ER membranes (MAMs).
In ERMCs we can also find SAR1 and ARF. These small GTPases involved in COPII and COPI vesicle assembly are also required to maintain mitochondrial morphology and function $(145,146)$. SAR1 regulates the size of mitochondrial ER contact sites by affecting the curvature of the membrane (146). While ARF1 and its guanine nucleotide exchange factor (GBF1) interact with mitochondrial protein MIRO, and their depletion affects mitochondrial morphology, autophagy, positioning, and movement within the cell $(145,147)$. These observations point to an important role of secretory pathway components in dynamics and physiology of mitochondria.

Overall, mitochondria are dynamic organelles whose function, morphology, distribution, and contacts with other organelles $(49,109,148)$ undergo changes in response to intracellular energy requirements, as well as other physiological and pathological stimuli (109).

\section{MITOCHONDRIA IN SECRETION Fulfilling ATP Requirements of the Secretion Process}

As mentioned before, many of the steps in the conventional secretion pathway demand energy (Table 1 and Figures 1, 2). Chaperones involved in protein translocation to the ER and protein folding consume ATP (5-7), as does protein quality control by the ERAD (8), transport and fusion of vesicles with target membranes $(2,9,51)$. Calcium signaling during regulated exocytosis also consumes ATP to maintain the levels of IP3 precursors and to pump calcium from the cytoplasm into the ER or to the extracellular space $(13,14,149)$. Overall, an increase in secretion of proteins is bound to challenge the cell's bioenergetics capacity; and inhibition of ATP synthesis, using inhibitors or uncouplers of oxidative phosphorylation, prevents the secretion of many proteins $(7,150-152)$.

The mechanism for ATP transport into the ER in mammalian cells was elusive for many years, and different possibilities, ranging from the existence of specific transporters to non-specific transport through anion channels or leaky membranes, have been proposed (4). However, recently protein SLC35B1 was identified as an ATP/ADP exchanger present in the ER membrane, and named AXER (153). Silencing the expression of SLC35B1/AXER reduced ATP levels in the ER of different cell lines and affected $\mathrm{BiP}$ dependent protein import activity and $\mathrm{Ca}^{2+}$ levels inside the ER $(153,154)$. A decrease in ATP in the ER was observed upon inhibition of SERCA or exposure to high cytosolic $\mathrm{Ca}^{2+}$ concentrations, suggesting that a $\mathrm{Ca}^{2+}$ gradient across the ER membrane is required for ATP transport into the ER (154). Inhibitors and uncouplers of oxidative phosphorylation lead to a decrease in ATP levels inside the ER as well, suggesting mitochondria is a relevant source of ATP for the ER (154, 155). Interestingly, several components of the mitochondrial ATP synthase complex immunoprecipitate with SLC35B1/AXER; along with proteins involved in ER protein import and folding such as BiP, calnexin, and Sec61 complex (153). Transfer of ATP from mitochondria to the ER probably occurs at ERMCs, where 
both organelles are in close proximity, yet this is still to be established (4).

\section{Calcium Buffering by Mitochondria in Exocytosis}

As we mentioned above, $\mathrm{Ca}^{2+}$ signals for exocytosis in many secretory cells. The increase in cytosolic $\mathrm{Ca}^{2+}$ concentration triggers vesicle fusion with the plasma membrane leading to the release of the cargo to the extracellular space. Calcium enters the cytosol through channels in the plasma or the ER membranes and several processes can affect the magnitude and duration of the signal for exocytosis, among them is $\mathrm{Ca}^{2+}$ uptake by mitochondria (13). Mitochondria are located in close proximity to $\mathrm{Ca}^{2+}$ channels in the ER and plasma membrane and can take up the ion through the VDAC and MCU channels in the OMM and IMM, respectively (144). This process is known as $\mathrm{Ca}^{2+}$ buffering and is driven by the negative potential across the IMM (144). Positioning of mitochondria near the sites of $\mathrm{Ca}^{2+}$ entry to the cytosol is also a requirement for the efficient uptake of the ion and effective $\mathrm{Ca}^{2+}$ signaling for exocytosis. This depends on proteins involved in mitochondrial dynamics and movement, such as MFN2, myosin, kinesin, TRAK, and MIRO (14, 156158). Of note, MIRO is both an adaptor protein, that links mitochondria to TRAK and kinesin, and a $\mathrm{Ca}^{2+}$ sensor which can regulate mitochondrial trafficking in response to changes in $\mathrm{Ca}^{2+}$ concentrations (157).

$\mathrm{Ca}^{2+}$ buffering has different effects on exocytosis, depending on the channel and cell type. Voltage-gated $\mathrm{Ca}^{2+}$ channels $\left(\mathrm{Ca}_{\mathrm{v}}\right)$ are present in the plasma membrane. These are activated by membrane depolarization and mediate $\mathrm{Ca}^{2+}$ influx in response to action potentials and other depolarizing signals (159). The increase in cytosolic $\mathrm{Ca}^{2+}$ stimulates exocytosis by binding syaptogamins that promote SNARE mediated vesicle fusion with the membrane (65). Mitochondria can be found in the cell cortex regions, near the sites of exocytosis and in this setting $\mathrm{Ca}^{2+}$ sequestering by mitochondria reduces vesicle release $(157,160$, 161).

In the plasma membrane we also find store-operated channels, known as $\mathrm{Ca}^{2+}$ release-activated (CRAC) channels. These are composed by Orai pore proteins, present in the plasma membrane, and STIM proteins from the ER and are activated by depletion of calcium stores in the ER $(13,149,158)$. When $\mathrm{Ca}^{2+}$ levels fall in the ER STIM proteins migrate to ER-plasma membrane junctions where they activate Orai channels, allowing the entry of $\mathrm{Ca}^{2+}$ into the cytosol. In turn, high cytosolic $\mathrm{Ca}^{2+}$ concentrations result in the closure of the pore and both a rapid and a slow $\mathrm{Ca}^{2+}$-dependent inactivation have been described (158). Mitochondrial translocation to the plasma membrane is essential to sustain $\mathrm{Ca}^{2+}$ influx through CRAC channels (162), since it prevents the slow inactivation of the CRAC channel without affecting the fast $\mathrm{Ca}^{2+}$-dependent inactivation (158). Inhibitors and uncouplers of electron transport and oxidative phosphorylation that dissipate the proton gradient prevent $\mathrm{Ca}^{2+}$ uptake by mitochondria and promote channel inactivation (163). Inhibition of kinesin- dependent transport of mitochondria to the plasma membrane also results in channel inactivation (162).
In the ER membrane the IP3R and ryanodine-sensitive receptors are the channels responsible for $\mathrm{Ca}^{2+}$ release to the cytosol $(13,14)$. IP3R is activated by IP3, a second messenger formed by hydrolysis of phosphatidylinositol 2,5-biphosphate by phospholipase $\mathrm{C}$. While ryanodine- sensitive receptors in secretory processes are activated by $\mathrm{Ca}^{2+}$ to release $\mathrm{Ca}^{2+}$ stored in the ER, in a process known as $\mathrm{Ca}^{2+}$ induced $\mathrm{Ca}^{2+}$ release that amplifies $\mathrm{Ca}^{2+}$ signaling (149). For both channels the response to cytosolic $\mathrm{Ca}^{2+}$ concentrations is bell shaped, since $\mathrm{Ca}^{2+}$ can act both as a positive or negative regulator of the channel depending on the concentration of the ion $(14,164)$. Thus, high concentrations of cytosolic $\mathrm{Ca}^{2+}$ result in a decrease in the activity of both I3PR and ryanodine sensitive receptors $(14,164)$. Uptake of $\mathrm{Ca}^{2+}$ by mitochondria prevents its accumulation precluding channel inhibition by high concentrations of $\mathrm{Ca}^{2+}(14)$.

From what we just described it is clear that mitochondria contribute to the regulation of intracellular $\mathrm{Ca}^{2+}$ concentrations, and therefore impact on the regulated exocytosis of many proteins and other signaling molecules such as neurotransmitters (Figure 1).

\section{Mitochondria in the Activation of NLRP3 Inflammasome}

The NLRP3 inflammasome is a multiprotein complex that participates in innate immunity. It is activated by multiple signals of infection, cellular damage, or stress, to produce inflammatory cytokines that trigger innate immune responses $(71,165)$. The sensor molecule NLRP3, the adaptor protein ASC and the effector caspase-1 form the complex, and recently the NIMArelated kinase 7 was identified as a fourth component. Upon stimulation, NLRP3 oligomerizes and recruits ASC that in turn recruits caspase 1 . The assembly of the NLRP3 inflammasome leads to the activation of caspase 1 that then cleaves proIL-1 $\beta$ and pro-IL-18, producing the mature cytokines IL-1 $\beta$ and IL-18 (71). As mentioned above the assembly of the NLRP3 inflammasome requires energy that is obtained from ATP hydrolysis catalyzed by NLRP3 NACHT domain (71). Mitochondria supplies ATP for this process but contributes also in other ways to the activation of the inflammasome.

NLRP3 inflammasome activation occurs in two steps, priming and NLRP3 activation. Priming involves the recognition of pathogen-associated molecular patterns (PAMPs, such as LPS) by pattern recognition receptors or binding of cytokines to receptors. These events lead to the activation of NF- $\mathrm{KB}$ and consequent upregulation of NLRP3, caspase 1 and IL- $1 \beta$ and IL-18 gene expression (71). The second step is the activation of NLRP3 by PAMPs or damage-associated molecular patterns (DAMPs, such as ATP); which involves multiple signaling events that result in the assembly of the complex [for exhaustive reviews see $(71,165)]$. Mitochondrial ROS and oxidized mtDNA released into the cytosol can trigger NLRP3 activation $(16,17)$.

Moreover, mitochondria are required for the assembly of the inflammasome. In absence of stimuli the NLRP3 is found in the cytoplasm associated with the ER, while its activation results in an association with mitochondria and enrichment in ERMCs 
(17). ASC and caspase 1 also migrate to mitochondria upon activation and are enriched at ERMCs $(17,18)$. In a recent report Elliot et al. suggest that priming results in NLRP3 and capase 1 linkage to the OMM, by association with the phospholipid cardiolipin, and mtROS are proposed to mediate cardiolipin transfer from the IMM to the OMM. Instead the association of ASC with mitochondria occurs in the activation step and does not require cardiolipin, but is dependent on NLRP3 and regulated by cytosolic $\mathrm{Ca}^{2+}$ (18). Interestingly in absence of VDAC, a relevant OMM channel and tether molecule in mitochondria-ER contact sites, activation is not observed (17).

Other mitochondrial proteins that are required for NLRP3 inflammasome activation are mitochondrial antiviral signaling proteins (MAVS). These proteins form aggregates in the OMM, associate with NLRP3 and promote its oligomerization, and activation of the inflammasome during RNA virus infections (166). The fusion protein MFN2 also participates in inflammasome activation and its silencing reduces IL-1 $\beta$ secretion in response to viral infection (167). Finally, dynein dependent transport of mitochondria along microtubules, toward the ER, is required for the activation of the inflammasome (168). Acetylation and deacetylation of tubulin by acetyltransferase MEC17 and the $\mathrm{NAD}^{+}$dependent deacetylase sirtuin 2 regulate microtubule transport of mitochondria to the ER and inflammasome activation (168).

In sum, mitochondria provide energy, signaling molecules and a structural scaffold for the assembly and activation of the NLRP3 inflammasome (Figure 1).

\section{BIOENERGETIC FAILURE AND SECRETORY DEFECTS IN DISEASE}

Considering the relevant roles of mitochondria in secretion it is not surprising that mitochondrial dysfunction underlies the pathogenesis of certain diseases. Herein we discuss the role of this organelle in some relevant physiological secretion processes, and present evidence linking bioenergetic failure to the development of disease.

\section{Insulin Secretion by Pancreatic $\beta$-Cells in Diabetes Mellitus}

Pancreatic $\beta$-cells are secretory cells located in the islets of Langerhans in the pancreas. Their main function is to synthesize and secrete insulin, a peptidic hormone responsible for regulating levels of glucose in the blood. Upon the increase in glucose concentrations in plasma, $\beta$-cells secrete insulin stored in the secretory granules and increase the synthesis of the hormone $(169,170)$.

Mitochondria play a key role in glucose-stimulated insulin secretion (GSIS) in pancreatic $\beta$-cells. In these cells glucose is metabolized in the glycolytic pathway and tricarboxylic acid cycle and results in ATP synthesis by oxidative phosphorylation. ATP promotes the closure of ATP-sensitive potassium channels and depolarization of the plasma membrane, leading to the opening of voltage-gated $\mathrm{Ca}^{2+}$ channels. Calcium influx then triggers the exocytosis of insulin granules (170). This process is termed $\mathrm{K}_{\mathrm{ATP}}$ - dependent GSIS. A $\mathrm{K}_{\mathrm{ATP}}$ - independent GSIS that depends on mitochondrial GTP and phosphoenolpyruvate metabolism has also been described $(171,172)$. Therefore, GSIS is extremely sensitive to genetic interventions and pharmacological agents that affect mitochondrial metabolism (22). This is clearly exemplified by the work of Kennedy et al. showing that depletion of mitochondria in the INS-1 insulin-secreting cell line precludes insulin secretion upon exposure to glucose (173). Likewise impairment of autophagy in pancreatic $\beta$-cells affects both mitochondrial respiration and GSIS, affecting glucose metabolism in vivo (174). As does inhibition of $\mathrm{Ca}^{2+}$ uptake by mitochondria after silencing of MCU or MICU1 gene expression, that also reduces ATP synthesis and insulin secretion (175).

Pancreatic $\beta$-cells present an active mitochondrial network where mitochondria constantly undergo fusion and fission events (176); and functional mitochondrial dynamics are required for GSIS in INS- 1 cells and primary $\beta$-cells (23). Overexpression of FIS1 in human pancreatic $\beta$-cells resulted in fragmentation and clustering of the mitochondrial network in the perinuclear area, a decrease in mitochondrial membrane potential and ATP synthesis, along with impairment of GSIS (177). Similar results where observed upon silencing of FIS1 expression that affected respiration rates and insulin secretion (178), overexpression of a dominant negative form of fission protein DRP1 and DRP1 silencing $(178,179)$. Alteration in the fusion machinery also affected insulin secretion. Overexpression of MFN1 resulted in hyperfusion and aggregation of mitochondria, reduced ATP levels and GSIS (177); while OPA1 ablation impaired glucosestimulated oxygen consumption rate, ATP production and insulin secretion (116).

It is clear that mitochondria play relevant roles in pancreatic $\beta$-cell secretion and a growing body of evidence links mitochondrial dysfunction to impaired insulin release in diabetes mellitus. Diabetes mellitus are a group of metabolic disorders characterized by hyperglycemia, resulting from defects in insulin secretion, insulin sensitivity, or both (180). In type 1 diabetes the cause is a total deficiency of insulin secretion, while in type 2 diabetes the cause is a combination of resistance to insulin action of the liver, skeletal muscle, and adipose tissue and an inadequate compensatory insulin secretory response $(180,181)$.

To start with, diabetes mellitus (type 1 and 2) is frequently observed in patients with inherited mitochondrial diseases, which are caused by defects in mtDNA or in nuclear genes encoding mitochondrial proteins that affect mitochondrial ATP synthesis (27). Several point mutations as well as deletions and rearrangements in mtDNA are strongly associated with the onset of diabetes $(27,182)$. As are mutations in nuclear genes encoding proteins involved in maintenance of the mitochondrial genome (27). The most common defect is the mutation m.3243A $>$ G in MT-TL1, which encodes a mitochondrial tRNA for leucine (183) and can lead to maternally inherited mitochondrial diabetes and deafness (MIDD) (27). Other point mutations in mitochondrial tRNA genes MT-TL1, MT-TK, MT-TS2, MT-TE, and MT-TT as well as in MT-ND6, a core subunit of complex I, have also been associated with diabetes mellitus $(27,184)$. Patients, carrying the m.3243A $>\mathrm{G}$ mutation presented reduced pancreatic insulin secretion (185-187), yet increases in insulin resistance 
and alterations in glucose metabolism cannot be discarded as causes of the disease (188).

Additionally profound changes in mitochondrial metabolism have been observed in pancreatic islets of type 2 diabetes patients and animal models. These include down regulation of components of the tricarboxylic cycle, ETC, ATP synthase and proteins involved in transport across the OMM and IMM (29, 189); as well as a decrease in glucose oxidation and a loss of glucose-stimulated increases in NADH, ATP, and oxygen consumption $(29,190-192)$. Other authors have observed an upregulation of uncoupling protein 2 (UCP-2), an IMM protein that dissipates the proton gradient; in pancreatic islets in type 2 diabetes $(190,193,194)$. Genetic deletion of UCP-2 in mice enhances islet ATP generation and insulin secretion during glucose stimulation and reduces hyperglycemia in the ob/ob mice (a well-known diabetes type 2 mouse model), providing further support for the role of UCP-2 in the pathogenesis of the disease (194). Regardless of the mechanism, the impairment in mitochondrial function in pancreatic $\beta$ cells precludes the glucose-induced increase in ATP levels. Lack of ATP will prevent the closure of ATP-sensitive $\mathrm{K}^{+}$channels (that is required to activate insulin secretion), impair the steps of the secretion pathway that require energy, resulting in lower levels of the circulating hormone and hyperglycemia.

\section{Neurotransmitter Release in Alzheimer's Disease}

Neurons are excitable cells that communicate with other cells at synapses. At the chemical synapse neurotransmitters are released by pre-synaptic neurons and bind their receptor at the postsynaptic terminal of target cells. Vesicle discharge at the synaptic cleft occurs in response to an influx of $\mathrm{Ca}^{2+}$ ions through voltagegated $\mathrm{Ca}^{2+}$ channels, triggered by the action potential. Three different pools of synaptic vesicles can be found in neurons readily releasable pool, the recycling pool, and the reserve pool. The vesicles in the readily releasable pool are released under moderate or intense neuronal activity, while vesicles from the reserve pool are recruited only upon intense stimulation. The latter constitute the majority of vesicles in presynaptic terminals $(28,160)$.

Maintaining the electrochemical gradients required for action potentials, transporting, discharging, recycling, and refilling synaptic vesicles, and regulating $\mathrm{Ca}^{2+}$ concentrations are energy demanding processes, that require functional mitochondria (28, 195). Regarding secretion in particular, loading of vesicles with neurotransmitters requires ATP to fuel the vacuole type $\mathrm{H}^{+}$ATPase (72). Besides, the mobilization of the reserve pool requires mitochondrial ATP that is used by myosins to move the vesicles along actin filaments (196). Additionally, $\mathrm{Ca}^{2+}$ signaling for vesicle exocytosis requires a constant export of the ion from the cytosol to the extracellular space, the ER and mitochondria. Plasma membrane $\mathrm{Ca}^{2+}$ ATPase (PMCA) and SERCA at the ER actively consume ATP (149). Mitochondria provide ATP for these pumps and directly remove $\mathrm{Ca}^{2+}$ from the cytosol through the MCU, as described previously $(28,196)$. Therefore, mitochondria are very abundant in neurons, where they form a highly dynamic network and their position and morphology change continually (28). In particular we find a high number of mitochondria at chemical synapses, where they provide ATP and buffer local rises in $\mathrm{Ca}^{2+}$ concentrations $(156,160,197)$. Since mitochondrial biogenesis and elimination (by mitophagy) occurs mainly in the neuronal soma, mitochondria travel between the axon terminals and the cell body (156) via the microtubule network. Motor proteins kinesin (anterograde) and dynein (retrograde), adaptor proteins TRAK, MIRO, and syntabulin as well as fission protein DRP1 are involved in mitochondrial trafficking $(28,156,196)$. Docking to microtubules, by syntaphilin, or to actin filaments limits mitochondrial mobility, retaining these organelles near to the sites where energy is required $(156,160)$.

Due to their high-energy demands, neurons are extremely affected in mitochondrial diseases, caused by mutations in mtDNA, and in other pathologies where mitochondrial function is compromised $(30,198)$. An example of the latter is Alzheimer's disease (AD), a neurodegenerative disease that involves progressive synaptic dysfunction and death of neurons in cortical and subcortical regions. $\mathrm{AD}$ is characterized by the accumulation of extracellular plaques of the peptide amyloid$\beta(\mathrm{A} \beta)$ and the formation of intracellular tangles of the microtubule-associated protein tau $(198,199)$.

Alterations in energy metabolism can be found in patients and animal models of AD. Reduced glucose metabolism was observed in brain regions affected by $\mathrm{AD}$ and the reduction correlated with cognitive decline in $\mathrm{AD}$ patients (200, 201). Analysis of brain samples from patients with AD showed abnormalities in mitochondrial cristae of hippocampal neurons (202); and reduced activity of enzymes involved in oxidative metabolism, namely pyruvate dehydrogenase (PDH), $\alpha$-ketoglutarate dehydrogenase and complex IV (203-205). Studies of brain mitochondrial function in a transgenic AD mouse model also revealed decreases in $\mathrm{PDH}$, complex IV and respiratory control ratios (RCR) and the decay in $\mathrm{PDH}$ and neuronal mitochondrial function preceded plaque formation (206). Moreover, in recent reports mitochondrial dysfunction was detected in hippocampal synaptosomes from transgenic AD rat model $(207,208)$. Decreased complex I activity, oxygen consumption rate, and ATP synthesis, along with an increase in hydrogen peroxide formation were measured, evidencing bioenergetics defects as well as oxidative stress at the presynaptic level (208). Alterations in mitochondrial dynamics and motility have also been observed in transgenic animal models of $\mathrm{AD}$, and result in lower number of mitochondria at the presynapses $(28,209,210)$. Regarding the causes behind bioenergetic failure in neurons, the $A \beta$ peptide has been found to accumulate in mitochondria $(206,211)$, where it directly impairs complex IV activity and ATP synthesis, and increases ROS formation (212). A $\beta$ can also directly affect mitochondrial dynamics, promoting mitochondrial fragmentation $(213,214)$. Defects in $\mathrm{Ca}^{2+}$ handling by mitochondria have also been observed in $\mathrm{AD}$ and $\mathrm{A} \beta$ can alter $\mathrm{Ca}^{2+}$ homeostasis at several levels (28, 73). Hyperphosphorylated tau also affects mitochodrial respiration and ATP synthesis, through the inhibition of complex I, impairs mitochondrial trafficking and induces mitochondrial fission (215). Overall in AD patients impaired mitochondrial 
energy metabolism, dynamics, $\mathrm{Ca}^{2+}$ homeostasis and oxidant formation are affected in neurons, at presynaptic terminals where neurotransmitter secretion takes place $(28,198)$.

Synapse loss is an early event in AD animal models and patients, and exhibits a strong correlation with cognitive deficits (73). Presynaptic release of neurotransmissors is affected in $\mathrm{AD}$, and $\mathrm{A} \beta$ can affect various steps of the secretion process including SNARE mediated fusion, recovery of vesicle membranes by endocytosis and $\mathrm{Ca}^{2+}$ homeostasis (73). The decrese in mitochondrial ATP synthesis and $\mathrm{Ca}^{2+}$ buffering, observed in $\mathrm{AD}$ at the presynaptic level, probably affects neurotransmitter release as well, and should be considered in the design of pharmacological strategies to target the disease (215). Supporting this concept are results obtained in a transgenic $\mathrm{AD}$ rat model, where treatment with a pharmacological inducer of mitochondrial biogenesis helped to recover mitochondrial function and protected against cognitive impairment (208).

\section{MITOCHONDRIA AND SECRETION IN OTHER PATHOLOGICAL SETTINGS}

In this section we present two examples of mitochondrial involvement in secretion processes that underlie pathology. This is not an extensive list, but rather a couple of interesting examples that support the idea that mitochondria might be interesting targets in the design of drugs to modulate secretory processes.

\section{Mast Cells Secretion in Atopic Dermatitis}

Mast cells are cells of hematopoietic origin that participate in host defense and immunity as well as tissue repair, wound healing, angiogenesis and are also responsible for the development of allergies (216). Mast cells can be activated by foreign pathogens, toxins chemical agents and particles, as well as by mediators of the immune response, such as immunoglobulin E (IgE) and complement components (216, 217). Upon activation mast cells release pre-stored mediators, and/or de novo synthesize and secrete a wide range of biologically active molecules (216). Pre-stored mediators include proteases, histamine, proteoglycans, and cytokines such as tumor necrosis factor (TNF), these are released immediately upon activation and are critical for initiating mast cell-mediated innate immune responses. Differently from pre-stored mediators, other molecules are synthesized de novo (i.e., lipids, cytokines, chemokines, antimicrobial peptides, growth and angiogenic factors) and play multiple roles in the immune response and other physiological and pathological processes $(216,217)$.

Mast cell degranulation and TNF secretion requires $\mathrm{Ca}^{2+}$ and mitochondrial ATP $(31,218)$. Interestingly stimuli that induce mast cell degranulation, promote the translocation of mitochondria to sites of exocytosis, close to the cell surface; and pharmacological or genetic inhibition of DRP1 inhibits both TNF secretion and mitochondrial translocation, in a cell line derived from human mast cell leukemia (24). In this report authors also show that calcium is required for DRP1 activation, as well as for mitochondrial translocation, and postulate that calcineurin is involved in DRP1 recruitment to mitochondrial surface
(24). The relevance of this observation was further supported by studies in human mast cells from patients with atopic dermatitis where increased degranulation and mitochondrial translocation was also observed, along with an increase in DRP1 and calcineurin expression (24). Mast cell degranulation also results in the secretion of mitochondrial particles outside cells including mtDNA, that in turn promote cytokine release from other mast cells, keratinocytes, and endothelial cells promoting inflammation (219).

\section{Senescence Associated Secretory Phenotype in Disease}

Cellular senescence is triggered in response to stress stimuli. Agents that damage DNA and strong mitogenic signals, such as the expression of oncogenes or loss of tumor suppressors, are strong senescence inducers (220-223). Senescent cells are characterized by permanent proliferation arrest, activation of the DNA damage response (DDR), increase in size and $\beta$-galactosidase activity and acquisition of a secretory phenotype $(224,225)$. The senescence-associated secretory phenotype (SASP) includes numerous cytokines and chemokines (e.g., IL-1 $\alpha$, IL-1 $\beta$ and IL-6, IL-8), growth factors and extracellular proteases. These mediators can induce senescence in neighboring cells, alter the extracellular matrix, contribute to local inflammation, and recruit immune cells among other effects (226-228); and contribute to several physiological and pathological processes $(229,230)$. At the transcriptional level most of the SASP components are regulated by NF-кB, C/EBP $\beta$, and NOTCH (231). IL-1 $\beta$ is a component of the SASP that is secreted through unconventional pathways (32). However, many of the SASP factors are most probably secreted through the conventional pathway, though this is practically unexplored.

Several studies support that establishment of senescence and the secretory phenotype is accompanied by metabolic reprogramming including increases in mitochondrial oxygen consumption rates, biogenesis and dynamics. In particular, important alterations have been observed in oncogene and therapy induced senescence (19-21, 232-235). Interestingly replicative senescent cells that present mitochondrial dysfunction $(236,237)$ secrete lower levels of cytokines and other mediators than oncogene induced senescent cells $(20,224)$.

Moreover, mitochondria are required to sustain the SASP and mitochondrial depletion down regulates the expression and secretion of multiple cytokines and other factors in senescent cells $(21,26)$. In oncogene induced senescence inhibition of carnitine palmitoyl transferase I (CPTI), a key enzyme of the mitochondrial fatty acid oxidation pathway, decreases the secretion of several cytokines and growth factors, but not of IL-1 $\beta$ (20). Similar results were obtained upon inhibition of nicotinamide phosphoribosyltransferase (NAMPT), and enzyme from the $\mathrm{NAD}^{+}$synthesis pathway (25), or silencing of mitochondrial sirtuin 3, known to impair mitochondrial electron transport $(26,238)$. Silencing of mitochondrial fusion proteins, MFN1 and 2 also impaired the secretion of IL-6 in senescent cells (19). Since mitofusins participate in the tethering of the mitochondria to the ER, these results suggest the association 
between these two organelles might be relevant in secretion processes in senescence. Finally mitochondrial ROS formation by the ETC $(239,240)$ and NADPH oxidase $4(241,242)$ are increased in senescent cells, and contribute to the establishment of senescence and the SASP [through the activation of NF-kB (243) and the DDR (244-246)]. Taken together these results point to a link between mitochondrial oxidative metabolism and dynamics and the proinflammatory secretory phenotype.

Since the SASP has been implied in numerous diseases (229, 247), the search for senolytics (that will kill senescent cells) or senomorphics (that will modulate the SASP) has become an active area of research $(248,249)$. Mitochondria appear as promising targets for the modulation of the SASP in pathological settings were senescent cells are involved.

\section{CONCLUDING REMARKS}

Herein we present evidence that mitochondria are required for the successful export of proteins to the extracellular space. Mitochondrial dynamics, bioenergetics and distribution as well as their interactions with other organelles, in particular with the ER, can undergo profound changes in response to secretion stimuli. Mitochondria contribute and support the secretion of proteins providing ATP for energy requiring processes, buffering $\mathrm{Ca}^{2+}$ concentrations and offering structural support and signals

\section{REFERENCES}

1. Kanapin A, Batalov S, Davis MJ, Gough J, Grimmond S, Kawaji H, et al. Mouse proteome analysis. Genome Res. (2003) 13(6B):1335-44. doi: 10.1101/gr.978703

2. Brandizzi F, Barlowe C. Organization of the ER-Golgi interface for membrane traffic control. Nat Rev Mol Cell Biol. (2013) 14:382-92. doi: $10.1038 / \mathrm{nrm} 3588$

3. Bajjalieh SM, Scheller RH. The biochemistry of neurotransmitter secretion. J Biol Chem. (1995) 270:1971-4. doi: 10.1074/jbc.270.5.1971

4. Depaoli MR, Hay JC, Graier WF, Malli R. The enigmatic ATP supply of the endoplasmic reticulum. Biol Rev Cambridge Philos Soc. (2019) 94:610-28. doi: $10.1111 /$ brv.12469

5. Braakman I, Helenius J, Helenius A. Role of ATP and disulphide bonds during protein folding in the endoplasmic reticulum. Nature. (1992) 356:260-2. doi: 10.1038/356260a0

6. Dorner AJ, Kaufman RJ. The levels of endoplasmic reticulum proteins and ATP affect folding and secretion of selective proteins. Biologicals. (1994) 22:103-12. doi: 10.1006/biol.1994.1016

7. Dorner AJ, Wasley LC, Kaufman RJ. Protein dissociation from GRP78 and secretion are blocked by depletion of cellular ATP levels. Proc Natl Acad Sci USA. (1990) 87:7429-32. doi: 10.1073/pnas.87.19.7429

8. Caramelo JJ, Parodi AJ. A sweet code for glycoprotein folding. FEBS Lett. (2015) 589:3379-87. doi: 10.1016/j.febslet.2015.07.021

9. Sweeney HL, Holzbaur ELF. Motor proteins. Cold Spring Harbor Perspect Biol. (2018) 10:a021931. doi: 10.1101/cshperspect.a021931

10. Sudhof TC, Rothman JE. Membrane fusion: grappling with SNARE and SM proteins. Science. (2009) 323:474-7. doi: 10.1126/science.116 1748

11. Anantharam A, Kreutzberger AJB. Unraveling the mechanisms of calcium-dependent secretion. J General Physiol. (2019) 151:417-34. doi: 10.1085/jgp.201812298

12. Carreras-Sureda A, Pihan P, Hetz C. Calcium signaling at the endoplasmic reticulum: fine-tuning stress responses. Cell Calcium. (2018) 70:24-31. doi: 10.1016/j.ceca.2017.08.004 for NLRP3 inflammasome activation. A better understanding, at the molecular level, of the role of mitochondria in secretion processes is required and will help in the development of new genetic and pharmacological strategies to modulate protein secretion in pathological contexts.

\section{AUTHOR CONTRIBUTIONS}

JM, IM, DT, and CQ contributed to the writing of the manuscript, CQ supervised all the activities. JM made the figures. All authors reviewed contents and approved the final version of the manuscript.

\section{FUNDING}

Agencia Nacional de Investigación e Innovación (ANII) FCE_1_2017_1_136021 to CQ and DM; Comisión Académica de Posgrados (CAP) of the UdelaR to JM and IM, Espacio Interdisciplinario Centros 2015, UdelaR; Programa de Desarrollo de las Ciencias Básicas (PEDECIBA).

\section{ACKNOWLEDGMENTS}

We thank Dr. Adriana Cassina for reading the manuscript and providing insightful comments.
13. Burgoyne RD, Morgan A. Secretory granule exocytosis. Physiol Rev. (2003) 83:581-632. doi: 10.1152/physrev.00031.2002

14. Rizzuto R, De Stefani D, Raffaello A, Mammucari C. Mitochondria as sensors and regulators of calcium signalling. Nat Rev Mol Cell Biol. (2012) 13:566-78. doi: $10.1038 / \mathrm{nrm} 3412$

15. Finkel T, Menazza S, Holmstrom KM, Parks RJ, Liu J, Sun J, et al. The ins and outs of mitochondrial calcium. Circul Res. (2015) 116:1810-9. doi: 10.1161/CIRCRESAHA.116.305484

16. Shimada K, Crother TR, Karlin J, Dagvadorj J, Chiba N, Chen S, et al. Oxidized mitochondrial DNA activates the NLRP3 inflammasome during apoptosis. Immunity. (2012) 36:401-14. doi: 10.1016/j.immuni.2012.01.009

17. Zhou R, Yazdi AS, Menu P, Tschopp J. A role for mitochondria in NLRP3 inflammasome activation. Nature. (2011) 469:221-5. doi: $10.1038 /$ nature 09663

18. Elliott EI, Miller AN, Banoth B, Iyer SS, Stotland A, Weiss JP, et al. Cutting edge: mitochondrial assembly of the NLRP3 Inflammasome complex is initiated at priming. J Immunol. (2018) 200:3047-52. doi: 10.4049/jimmunol.1701723

19. Martinez J, Tarallo D, Martinez-Palma L, Victoria S, Bresque M, RodriguezBottero S, et al. Mitofusins modulate the increase in mitochondrial length, bioenergetics and secretory phenotype in therapy-induced senescent melanoma cells. Biochem J. (2019) 476:2463-86. doi: 10.1042/BCJ20190405

20. Quijano C, Cao L, Fergusson MM, Romero H, Liu J, Gutkind S, et al. Oncogene-induced senescence results in marked metabolic and bioenergetic alterations. Cell Cycle. (2012) 11:1383-92. doi: 10.4161/cc.19800

21. Correia-Melo C, Marques FD, Anderson R, Hewitt G, Hewitt R, Cole J, et al. Mitochondria are required for pro-ageing features of the senescent phenotype. EMBO J. (2016) 35:724-42. doi: 10.15252/embj.201592862

22. Jhun BS, Lee H, Jin ZG, Yoon Y. Glucose stimulation induces dynamic change of mitochondrial morphology to promote insulin secretion in the insulinoma cell line INS-1E. PLoS ONE. (2013) 8:e60810. doi: 10.1371/journal.pone.0060810

23. Stiles L, Shirihai OS. Mitochondrial dynamics and morphology in beta-cells. Best Pract Res Clin Endocrinol Metab. (2012) 26:725-38. doi: 10.1016/j.beem.2012.05.004 
24. Zhang B, Alysandratos KD, Angelidou A, Asadi S, Sismanopoulos N, Delivanis DA, et al. Human mast cell degranulation and preformed TNF secretion require mitochondrial translocation to exocytosis sites: relevance to atopic dermatitis. J Allergy Clin Immunol. (2011) 127:1522-31 e8. doi: 10.1016/j.jaci.2011.02.005

25. Nacarelli T, Lau L, Fukumoto T, Zundell J, Fatkhutdinov N, Wu S, et al. $\mathrm{NAD}(+)$ metabolism governs the proinflammatory senescence-associated secretome. Nat Cell Biol. (2019) 21:397-407. doi: 10.1038/s41556-019-0287-4

26. Wiley CD, Velarde MC, Lecot P, Liu S, Sarnoski EA, Freund A, et al. Mitochondrial dysfunction induces senescence with a distinct secretory phenotype. Cell Metab. (2016) 23:303-14. doi: 10.1016/j.cmet.2015.11.011

27. Chow J, Rahman J, Achermann JC, Dattani MT, Rahman S. Mitochondrial disease and endocrine dysfunction. Nat Rev Endocrinol. (2017) 13:92-104. doi: $10.1038 /$ nrendo.2016.151

28. Devine MJ, Kittler JT. Mitochondria at the neuronal presynapse in health and disease. Nat Rev Neurosci. (2018) 19:63-80. doi: 10.1038/nrn.2017.170

29. Haythorne E, Rohm M, van de Bunt M, Brereton MF, Tarasov AI, Blacker TS, et al. Diabetes causes marked inhibition of mitochondrial metabolism in pancreatic beta-cells. Nat Commun. (2019) 10:2474. doi: 10.1038/s41467-019-10189-x

30. Wallace DC. A mitochondrial paradigm of metabolic and degenerative diseases, aging, and cancer: a dawn for evolutionary medicine. Annu Rev Genet. (2005) 39:359-407. doi: 10.1146/annurev.genet.39.110304.095751

31. Weatherly LM, Shim J, Hashmi HN, Kennedy RH, Hess ST, Gosse JA. Antimicrobial agent triclosan is a proton ionophore uncoupler of mitochondria in living rat and human mast cells and in primary human keratinocytes. J Appl Toxicol. (2016) 36:777-89. doi: 10.1002/jat.3209

32. Kim J, Gee HY, Lee MG. Unconventional protein secretion - new insights into the pathogenesis and therapeutic targets of human diseases. J Cell Sci. (2018) 131:jcs213686. doi: 10.1242/jcs.213686

33. Viotti C. ER to Golgi-dependent protein secretion: the conventional pathway. Methods Mol Biol. (2016) 1459:3-29. doi: 10.1007/978-1-4939-3804-9_1

34. Lee MC, Miller EA, Goldberg J, Orci L, Schekman R. Bi-directional protein transport between the ER and Golgi. Annu Rev Cell Dev Biol. (2004) 20:87123. doi: 10.1146/annurev.cellbio.20.010403.105307

35. Bonifacino JS, Glick BS. The mechanisms of vesicle budding and fusion. Cell. (2004) 116:153-66. doi: 10.1016/S0092-8674(03)01079-1

36. Hehnly H, Stamnes M. Regulating cytoskeleton-based vesicle motility. FEBS Lett. (2007) 581:2112-8. doi: 10.1016/j.febslet.2007.01.094

37. Mandon EC, Trueman SF, Gilmore R. Protein translocation across the rough endoplasmic reticulum. Cold Spring Harbor Perspect Biol. (2013) 5:a013342. doi: $10.1101 /$ cshperspect.a013342

38. Benham AM. Protein secretion and the endoplasmic reticulum. Cold Spring Harbor Perspect Biol. (2012) 4:a012872. doi: 10.1101/cshperspect.a012872

39. Connolly T, Gilmore R. The signal recognition particle receptor mediates the GTP-dependent displacement of SRP from the signal sequence of the nascent polypeptide. Cell. (1989) 57:599-610. doi: 10.1016/0092-8674(89)90129-3

40. Zimmermann R, Eyrisch S, Ahmad M, Helms V. Protein translocation across the ER membrane. Biochim Biophys Acta. (2011) 1808:912-24. doi: 10.1016/j.bbamem.2010.06.015

41. Pobre KFR, Poet GJ, Hendershot LM. The endoplasmic reticulum (ER) chaperone $\mathrm{BiP}$ is a master regulator of ER functions: getting by with a little help from ERdj friends. J Biol Chem. (2019) 294:2098-108. doi: 10.1074/jbc.REV118.002804

42. Melnyk A, Rieger H, Zimmermann R. Co-chaperones of the mammalian endoplasmic reticulum. Sub Cell Biochem. (2015) 78:179-200. doi: 10.1007/978-3-319-11731-7_9

43. Nelson DL, Cox MM. Lehninger Principles of Biochemistry. 6th ed. New York, NY: W. H. Freeman and Company (2008).

44. Frey S, Leskovar A, Reinstein J, Buchner J. The ATPase cycle of the endoplasmic chaperone Grp94. J Biol Chem. (2007) 282:35612-20. doi: 10.1074/jbc.M704647200

45. Olzmann JA, Kopito RR, Christianson JC. The mammalian endoplasmic reticulum-associated degradation system. Cold Spring Harbor Perspect Biol. (2013) 5:a013185. doi: 10.1101/cshperspect.a013185

46. Ruggiano A, Foresti O, Carvalho P. Quality control: ERassociated degradation: protein quality control and beyond.
$J \quad C e l l$
Biol.
(2014)
204:869-79.
doi:
$10.1083 /$ jcb. 2013

47. Barlowe C, Helenius A. Cargo capture and bulk flow in the early secretory pathway. Annu Rev Cell Dev Biol. (2016) 32:197-222. doi: 10.1146/annurev-cellbio-111315-125016

48. Szul T, Sztul E. COPII and COPI traffic at the ER-Golgi interface. Physiology. (2011) 26:348-64. doi: 10.1152/physiol.00017.2011

49. Barlan K, Gelfand VI. Microtubule-based transport and the distribution, tethering, and organization of organelles. Cold Spring Harbor Perspect Biol. (2017) 9:a025817. doi: 10.1101/cshperspect.a025817

50. Gutierrez LM. New insights into the role of the cortical cytoskeleton in exocytosis from neuroendocrine cells. Int Rev Cell Mol Biol. (2012) 295:10937. doi: 10.1016/B978-0-12-394306-4.00009-5

51. Rizo J, Xu J. The synaptic vesicle release machinery. Annu Rev Biophys. (2015) 44:339-67. doi: 10.1146/annurev-biophys-060414-034057

52. Dempski RE Jr, Imperiali B. Oligosaccharyl transferase: gatekeeper to the secretory pathway. Curr Opin Chem Biol. (2002) 6:844-50. doi: 10.1016/S1367-5931(02)00390-3

53. Mohorko E, Glockshuber R, Aebi M. Oligosaccharyltransferase: the central enzyme of N-linked protein glycosylation. J Inherited Metab Dis. (2011) 34:869-78. doi: 10.1007/s10545-011-9337-1

54. Parodi AJ. Protein glucosylation and its role in protein folding. Annu Rev Biochem. (2000) 69:69-93. doi: 10.1146/annurev.biochem.6 9.1.69

55. Caramelo JJ, Parodi AJ. Getting in and out from calnexin/calreticulin cycles. J Biol Chem. (2008) 283:10221-5. doi: 10.1074/jbc.R700048200

56. Williams DB. Beyond lectins: the calnexin/calreticulin chaperone system of the endoplasmic reticulum. J Cell Sci. (2006) 119(Pt 4):615-23. doi: $10.1242 /$ jcs. 02856

57. Periasamy M, Kalyanasundaram A. SERCA pump isoforms: their role in calcium transport and disease. Muscle Nerve. (2007) 35:430-42. doi: $10.1002 /$ mus. 20745

58. Svedine S, Wang T, Halaban R, Hebert DN. Carbohydrates act as sorting determinants in ER-associated degradation of tyrosinase. J Cell Sci. (2004) 117(Pt 14):2937-49. doi: 10.1242/jcs.01154

59. Anelli T, Sitia R. Protein quality control in the early secretory pathway. EMBO J. (2008) 27:315-27. doi: 10.1038/sj.emboj.7601974

60. Barlowe C, Orci L, Yeung T, Hosobuchi M, Hamamoto S, Salama N, et al. COPII: a membrane coat formed by sec proteins that drive vesicle budding from the endoplasmic reticulum. Cell. (1994) 77:895-907. doi: 10.1016/0092-8674(94)90138-4

61. Miller EA, Beilharz TH, Malkus PN, Lee MC, Hamamoto S, Orci L, et al. Multiple cargo binding sites on the COPII subunit Sec24p ensure capture of diverse membrane proteins into transport vesicles. Cell. (2003) 114:497-509. doi: 10.1016/S0092-8674(03)00609-3

62. Bi X, Mancias JD, Goldberg J. Insights into COPII coat nucleation from the structure of Sec23.Sar1 complexed with the active fragment of Sec31. Dev Cell. (2007) 13:635-45. doi: 10.1016/j.devcel.2007.10.006

63. Jackson CL, Bouvet S. Arfs at a glance. J Cell Sci. (2014) 127(Pt 19):4103-9. doi: $10.1242 /$ jcs.144899

64. Ross JL, Ali MY, Warshaw DM. Cargo transport: molecular motors navigate a complex cytoskeleton. Curr Opin Cell Biol. (2008) 20:41-7. doi: 10.1016/j.ceb.2007.11.006

65. Pang ZP, Sudhof TC. Cell biology of $\mathrm{Ca}^{2+}$-triggered exocytosis. Curr Opin Cell Biol. (2010) 22:496-505. doi: 10.1016/j.ceb.2010.05.001

66. Li P, Bademosi AT, Luo J, Meunier FA. Actin remodeling in regulated exocytosis: toward a mesoscopic view. Trends Cell Biol. (2018) 28:685-97. doi: 10.1016/j.tcb.2018.04.004

67. Wen PJ, Grenklo S, Arpino G, Tan X, Liao HS, Heureaux J, et al. Actin dynamics provides membrane tension to merge fusing vesicles into the plasma membrane. Nat Commun. (2016) 7:12604. doi: $10.1038 /$ ncomms 12604

68. Rabouille C. Pathways of unconventional protein secretion. Trends Cell Biol. (2017) 27:230-40. doi: 10.1016/j.tcb.2016.11.007

69. Martin-Sanchez F, Diamond C, Zeitler M, Gomez AI, Baroja-Mazo A, Bagnall J, et al. Inflammasome-dependent IL-1 $\beta$ release depends upon membrane permeabilisation. Cell Death Different. (2016) 23:1219-31. doi: $10.1038 /$ cdd.2015.176 
70. Netea MG, van de Veerdonk FL, van der Meer JW, Dinarello CA, Joosten LA. Inflammasome-independent regulation of IL-1-family cytokines. Annu Rev Immunol. (2015) 33:49-77. doi: 10.1146/annurev-immunol-032414-112306

71. Swanson KV, Deng M, Ting JP. The NLRP3 inflammasome: molecular activation and regulation to therapeutics. Nat Rev Immunol. (2019) 19:47789. doi: 10.1038/s41577-019-0165-0

72. Blakely RD, Edwards RH. Vesicular and plasma membrane transporters for neurotransmitters. Cold Spring Harbor Perspect Biol. (2012) 4:a025817. doi: $10.1101 /$ cshperspect.a005595

73. Ovsepian SV, O’Leary VB, Zaborszky L, Ntziachristos V, Dolly JO. Synaptic vesicle cycle and amyloid beta: biting the hand that feeds. Alzheimer's Dement. (2018) 14:502-13. doi: 10.1016/j.jalz.2018.01.011

74. Chanaday NL, Cousin MA, Milosevic I, Watanabe S, Morgan JR. The synaptic vesicle cycle revisited: new insights into the modes and mechanisms. J Neurosci. (2019) 39:8209-16. doi: 10.1523/JNEUROSCI.1158-19.2019

75. Cogliati S, Enriquez JA, Scorrano L. Mitochondrial cristae: where beauty meets functionality. Trends Biochem Sci. (2016) 41:261-73. doi: 10.1016/j.tibs.2016.01.001

76. Acin-Perez R, Fernandez-Silva P, Peleato ML, Perez-Martos A, Enriquez JA. Respiratory active mitochondrial supercomplexes. Mol Cell. (2008) 32:52939. doi: 10.1016/j.molcel.2008.10.021

77. Letts JA, Sazanov LA. Clarifying the supercomplex: the higher-order organization of the mitochondrial electron transport chain. Nat Struct Mol Biol. (2017) 24:800-8. doi: 10.1038/nsmb.3460

78. Davies KM, Strauss M, Daum B, Kief JH, Osiewacz HD, Rycovska A, et al. Macromolecular organization of ATP synthase and complex I in whole mitochondria. Proc Natl Acad Sci USA. (2011) 108:14121-6. doi: 10.1073/pnas.1103621108

79. Harner M, Korner C, Walther D, Mokranjac D, Kaesmacher J, Welsch U, et al. The mitochondrial contact site complex, a determinant of mitochondrial architecture. EMBO J. (2011) 30:4356-70. doi: 10.1038/emboj.2011.379

80. Cogliati S, Frezza C, Soriano ME, Varanita T, Quintana-Cabrera R, Corrado M, et al. Mitochondrial cristae shape determines respiratory chain supercomplexes assembly and respiratory efficiency. Cell. (2013) 155:160-71. doi: 10.1016/j.cell.2013.08.032

81. Spinelli JB, Haigis MC. The multifaceted contributions of mitochondria to cellular metabolism. Nat Cell Biol. (2018) 20:745-54. doi: 10.1038/s41556-018-0124-1

82. Neupane P, Bhuju S, Thapa N, Bhattarai HK. ATP synthase: structure, function and inhibition. Biomol Concepts. (2019) 10:1-10. doi: 10.1515/bmc-2019-0001

83. Watt IN, Montgomery MG, Runswick MJ, Leslie AG, Walker JE. Bioenergetic cost of making an adenosine triphosphate molecule in animal mitochondria. Proc Natl Acad Sci USA. (2010) 107:16823-7. doi: 10.1073/pnas.1011099107

84. Quijano C, Trujillo M, Castro L, Trostchansky A. Interplay between oxidant species and energy metabolism. Redox Biol. (2016) 8:28-42. doi: 10.1016/j.redox.2015.11.010

85. Turrens JF. Mitochondrial formation of reactive oxygen species. J Physiol. (2003) 552(Pt 2):335-44. doi: 10.1113/jphysiol.2003.049478

86. Radi R. Oxygen radicals, nitric oxide, and peroxynitrite: redox pathways in molecular medicine. Proc Natl Acad Sci USA. (2018) 115:5839-48. doi: 10.1073/pnas.1804932115

87. Cox AG, Winterbourn CC, Hampton MB. Mitochondrial peroxiredoxin involvement in antioxidant defence and redox signalling. Biochem J. (2010) 425:313-25. doi: 10.1042/BJ20091541

88. Fridovich I. Superoxide radical and superoxide dismutases. Annu Rev Biochem. (1995) 64:97-112. doi: 10.1146/annurev.bi.64.070195.000525

89. Finkel T, Holbrook NJ. Oxidants, oxidative stress and the biology of ageing. Nature. (2000) 408:239-47. doi: 10.1038/35041687

90. Radi R, Cassina A, Hodara R, Quijano C, Castro L. Peroxynitrite reactions and formation in mitochondria. Free Radic Biol Med. (2002) 33:1451-64. doi: 10.1016/S0891-5849(02)01111-5

91. Youle RJ, van der Bliek AM. Mitochondrial fission, fusion, and stress. Science. (2012) 337:1062-5. doi: 10.1126/science.1219855

92. Lee H, Smith SB, Yoon Y. The short variant of the mitochondrial dynamin OPA1 maintains mitochondrial energetics and cristae structure. J Biol Chem. (2017) 292:7115-30. doi: 10.1074/jbc.M116.762567
93. Ishihara N, Eura Y, Mihara K. Mitofusin 1 and 2 play distinct roles in mitochondrial fusion reactions via GTPase activity. J Cell Sci. (2004) 117(Pt 26):6535-46. doi: 10.1242/jcs.01565

94. Koshiba T, Detmer SA, Kaiser JT, Chen H, McCaffery JM, Chan DC. Structural basis of mitochondrial tethering by mitofusin complexes. Science. (2004) 305:858-62. doi: 10.1126/science.1099793

95. Choi SY, Huang P, Jenkins GM, Chan DC, Schiller J, Frohman MA. A common lipid links Mfn-mediated mitochondrial fusion and SNAREregulated exocytosis. Nat Cell Biol. (2006) 8:1255-62. doi: 10.1038/ncb1487

96. Smirnova E, Griparic L, Shurland DL, van der Bliek AM. Dynamin-related protein Drp1 is required for mitochondrial division in mammalian cells. $\mathrm{Mol}$ Biol Cell. (2001) 12:2245-56. doi: 10.1091/mbc.12.8.2245

97. Otera H, Wang C, Cleland MM, Setoguchi K, Yokota S, Youle RJ, et al. Mff is an essential factor for mitochondrial recruitment of Drp1 during mitochondrial fission in mammalian cells. J Cell Biol. (2010) 191:1141-58. doi: $10.1083 /$ jcb. 201007152

98. Losón OC, Song Z, Chen H, Chan DC. Fis1, Mff, MiD49, and MiD51 mediate Drp1 recruitment in mitochondrial fission. Mol Biol Cell. (2013) 24:659-67. doi: 10.1091/mbc.e12-10-0721

99. Zhang Y, Chan DC. Structural basis for recruitment of mitochondrial fission complexes by Fis1. Proc Natl Acad Sci USA. (2007) 104:18526-30. doi: 10.1073/pnas.0706441104

100. Friedman JR, Lackner LL, West M, DiBenedetto JR, Nunnari J, Voeltz GK. ER tubules mark sites of mitochondrial division. Science. (2011) 334:358-62. doi: 10.1126/science. 1207385

101. De Vos KJ, Allan VJ, Grierson AJ, Sheetz MP. Mitochondrial function and actin regulate dynamin-related protein 1-dependent mitochondrial fission. Curr Biol. (2005) 15:678-83. doi: 10.1016/j.cub.2005.02.064

102. Korobova F, Gauvin TJ, Higgs HN. A role for myosin II in mammalian mitochondrial fission. Curr Biol. (2014) 24:409-14. doi: 10.1016/j.cub.2013.12.032

103. Manor U, Bartholomew S, Golani G, Christenson E, Kozlov M, Higgs $\mathrm{H}$, et al. A mitochondria-anchored isoform of the actin-nucleating spire protein regulates mitochondrial division. eLife. (2015) 4:e08828. doi: $10.7554 /$ eLife.08828

104. Pagliuso A, Tham TN, Stevens JK, Lagache T, Persson R, Salles A, et al. A role for septin 2 in Drp1-mediated mitochondrial fission. EMBO Rep. (2016) 17:858-73. doi: 10.15252/embr.201541612

105. Korobova F, Ramabhadran V, Higgs HN. An actin-dependent step in mitochondrial fission mediated by the ER-associated formin INF2. Science. (2013) 339:464-7. doi: 10.1126/science.1228360

106. Kar UP, Dey H, Rahaman A. Regulation of dynamin family proteins by post-translational modifications. J Biosci. (2017) 42:333-44. doi: 10.1007/s12038-017-9680-y

107. Bulthuis EP, Adjobo-Hermans MJW, Willems P, Koopman WJH. Mitochondrial morphofunction in mammalian cells. Antioxidants Redox Signal. (2019) 30:2066-109. doi: 10.1089/ars.2018.7534

108. Sauvanet C, Duvezin-Caubet S, di Rago JP, Rojo M. Energetic requirements and bioenergetic modulation of mitochondrial morphology and dynamics. Semin Cell Dev Biol. (2010) 21:558-65. doi: 10.1016/j.semcdb.2009.1 2.006

109. Mishra P, Chan DC. Metabolic regulation of mitochondrial dynamics. J Cell Biol. (2016) 212:379-87. doi: 10.1083/jcb.201511036

110. Schrepfer E, Scorrano L. Mitofusins, from mitochondria to metabolism. Mol cell. (2016) 61:683-94. doi: 10.1016/j.molcel.2016.02.022

111. Bach D, Pich S, Soriano FX, Vega N, Baumgartner B, Oriola J, et al. Mitofusin-2 determines mitochondrial network architecture and mitochondrial metabolism. A novel regulatory mechanism altered in obesity. J Biol Chem. (2003) 278:17190-7. doi: 10.1074/jbc.M21275 4200

112. Mourier A, Motori E, Brandt T, Lagouge M, Atanassov I, Galinier A, et al. Mitofusin 2 is required to maintain mitochondrial coenzyme Q levels. J Cell Biol. (2015) 208:429-42. doi: 10.1083/jcb.201 411100

113. Pich S, Bach D, Briones P, Liesa M, Camps M, Testar X, et al. The CharcotMarie-Tooth type 2A gene product, Mfn2, up-regulates fuel oxidation through expression of OXPHOS system. Hum Mol Genet. (2005) 14:1405-15. doi: $10.1093 / \mathrm{hmg} / \mathrm{ddi} 149$ 
114. Son JM, Sarsour EH, Kakkerla Balaraju A, Fussell J, Kalen AL, Wagner $\mathrm{BA}$, et al. Mitofusin 1 and optic atrophy 1 shift metabolism to mitochondrial respiration during aging. Aging Cell. (2017) 16:1136-45. doi: 10.1111/acel.12649

115. Chen H, Chomyn A, Chan DC. Disruption of fusion results in mitochondrial heterogeneity and dysfunction. J Biol Chem. (2005) 280:26185-92. doi: 10.1074/jbc.M503062200

116. Zhang Z, Wakabayashi N, Wakabayashi J, Tamura Y, Song WJ, Sereda S, et al. The dynamin-related GTPase Opal is required for glucose-stimulated ATP production in pancreatic beta cells. Mol Biol Cell. (2011) 22:2235-45. doi: 10.1091/mbc.e10-12-0933

117. Patten DA, Wong J, Khacho M, Soubannier V, Mailloux RJ, PilonLarose $\mathrm{K}$, et al. OPA1-dependent cristae modulation is essential for cellular adaptation to metabolic demand. EMBO J. (2014) 33:2676-91. doi: 10.15252/embj.201488349

118. Quintero OA, DiVito MM, Adikes RC, Kortan MB, Case LB, Lier AJ, et al. Human Myo19 is a novel myosin that associates with mitochondria. Curr Biol. (2009) 19:2008-13. doi: 10.1016/j.cub.2009.10.026

119. Glater EE, Megeath LJ, Stowers RS, Schwarz TL. Axonal transport of mitochondria requires milton to recruit kinesin heavy chain and is light chain independent. J Cell Biol. (2006) 173:545-57. doi: $10.1083 /$ jcb. 200601067

120. Morlino G, Barreiro O, Baixauli F, Robles-Valero J, Gonzalez-Granado JM, Villa-Bellosta R, et al. Miro-1 links mitochondria and microtubule Dynein motors to control lymphocyte migration and polarity. Mol Cell Biol. (2014) 34:1412-26. doi: 10.1128/MCB.01177-13

121. van Spronsen M, Mikhaylova M, Lipka J, Schlager MA, van den Heuvel DJ, Kuijpers M, et al. TRAK/Milton motor-adaptor proteins steer mitochondrial trafficking to axons and dendrites. Neuron. (2013) 77:485502. doi: 10.1016/j.neuron.2012.11.027

122. Lopez-Domenech G, Covill-Cooke C, Ivankovic D, Halff EF, Sheehan DF, Norkett R, et al. Miro proteins coordinate microtubule- and actin-dependent mitochondrial transport and distribution. EMBO J. (2018) 37:321-36. doi: 10.15252/embj.201696380

123. Modi S, Lopez-Domenech G, Halff EF, Covill-Cooke C, Ivankovic D, Melandri D, et al. Miro clusters regulate ER-mitochondria contact sites and link cristae organization to the mitochondrial transport machinery. Nat Commun. (2019) 10:4399. doi: 10.1038/s41467-019-12382-4

124. Dolman NJ, Gerasimenko JV, Gerasimenko OV, Voronina SG, Petersen OH, Tepikin AV. Stable Golgi-mitochondria complexes and formation of Golgi $\mathrm{Ca}(2+)$ gradients in pancreatic acinar cells. J Biol Chem. (2005) 280:15794-9. doi: 10.1074/jbc.M412694200

125. Moltedo O, Remondelli P, Amodio G. The mitochondria-endoplasmic reticulum contacts and their critical role in aging and age-associated diseases. Front Cell Dev Biol. (2019) 7:172. doi: 10.3389/fcell.2019.00172

126. Xia M, Zhang Y, Jin K, Lu Z, Zeng Z, Xiong W. Communication between mitochondria and other organelles: a brand-new perspective on mitochondria in cancer. Cell Biosci. (2019) 9:27. doi: 10.1186/s13578-019-0289-8

127. Elbaz Y, Schuldiner M. Staying in touch: the molecular era of organelle contact sites. Trends Biochem Sci. (2011) 36:616-23. doi: 10.1016/j.tibs.2011.08.004

128. Cosson P, Marchetti A, Ravazzola M, Orci L. Mitofusin-2 independent juxtaposition of endoplasmic reticulum and mitochondria: an ultrastructural study. PLoS ONE. (2012) 7:e46293. doi: 10.1371/journal.pone.0046293

129. Filadi R, Greotti E, Turacchio G, Luini A, Pozzan T, Pizzo P. Mitofusin 2 ablation increases endoplasmic reticulum-mitochondria coupling. Proc Natl Acad Sci USA. (2015) 112:E2174-81. doi: 10.1073/pnas. 1504880112

130. de Brito OM, Scorrano L. Mitofusin 2 tethers endoplasmic reticulum to mitochondria. Nature. (2008) 456:605-10. doi: 10.1038/nature07534

131. Naon D, Zaninello M, Giacomello M, Varanita T, Grespi F, Lakshminaranayan $\mathrm{S}$, et al. Critical reappraisal confirms that mitofusin 2 is an endoplasmic reticulum-mitochondria tether. Proc Natl Acad Sci USA. (2016) 113:11249-54. doi: 10.1073/pnas.1606786113

132. Filadi R, Greotti E, Turacchio G, Luini A, Pozzan T, Pizzo P. Presenilin 2 modulates endoplasmic reticulum-mitochondria coupling by tuning the antagonistic effect of mitofusin 2. Cell Rep. (2016) 15:2226-38. doi: $10.1016 /$ j.celrep.2016.05.013
133. Sugiura A, Nagashima S, Tokuyama T, Amo T, Matsuki Y, Ishido S, et al. MITOL regulates endoplasmic reticulum-mitochondria contacts via mitofusin2. Mol Cell. (2013) 51:20-34. doi: 10.1016/j.molcel.2013.04.023

134. Cerqua C, Anesti V, Pyakurel A, Liu D, Naon D, Wiche G, et al. Trichoplein/mitostatin regulates endoplasmic reticulum-mitochondria juxtaposition. EMBO Rep. (2010) 11:854-60. doi: 10.1038/embor.2010.151

135. De Vos KJ, Morotz GM, Stoica R, Tudor EL, Lau KF, Ackerley S, et al. VAPB interacts with the mitochondrial protein PTPIP51 to regulate calcium homeostasis. Hum Mol Genet. (2012) 21:1299-311. doi: 10.1093/hmg/ddr559

136. Gomez-Suaga P, Paillusson S, Stoica R, Noble W, Hanger DP, Miller CCJ. The ER-mitochondria tethering complex VAPB-PTPIP51 regulates autophagy. Curr Biol. (2017) 27:371-85. doi: 10.1016/j.cub.2016.12.038

137. Gomez-Suaga P, Perez-Nievas BG, Glennon EB, Lau DHW, Paillusson S, Morotz GM, et al. The VAPB-PTPIP51 endoplasmic reticulummitochondria tethering proteins are present in neuronal synapses and regulate synaptic activity. Acta Neuropathol Commun. (2019) 7:35. doi: 10.1186/s40478-019-0688-4

138. Raturi A, Simmen T. Where the endoplasmic reticulum and the mitochondrion tie the knot: the mitochondria-associated membrane (MAM). Biochim Biophys Acta. (2013) 1833:213-24. doi: 10.1016/j.bbamcr.2012.04.013

139. Lee S, Lee KS, Huh S, Liu S, Lee DY, Hong SH, et al. Polo kinase phosphorylates miro to control ER-mitochondria contact sites and mitochondrial $\mathrm{Ca}(2+)$ homeostasis in neural stem cell development. Dev Cell. (2016) 37:174-89. doi: 10.1016/j.devcel.2016.03.023

140. Lynes EM, Bui M, Yap MC, Benson MD, Schneider B, Ellgaard L, et al. Palmitoylated TMX and calnexin target to the mitochondria-associated membrane. EMBO J. (2012) 31:457-70. doi: 10.1038/emboj.2011.384

141. Lynes EM, Raturi A, Shenkman M, Ortiz Sandoval C, Yap MC, Wu $\mathrm{J}$, et al. Palmitoylation is the switch that assigns calnexin to quality control or ER $\mathrm{Ca}^{2+}$ signaling. J Cell Sci. (2013) 126(Pt 17):3893-903. doi: $10.1242 /$ jcs. 125856

142. Baughman JM, Perocchi F, Girgis HS, Plovanich M, Belcher-Timme CA, Sancak Y, et al. Integrative genomics identifies MCU as an essential component of the mitochondrial calcium uniporter. Nature. (2011) 476:3415. doi: $10.1038 /$ nature 10234

143. De Stefani D, Raffaello A, Teardo E, Szabo I, Rizzuto R. A forty-kilodalton protein of the inner membrane is the mitochondrial calcium uniporter. Nature. (2011) 476:336-40. doi: 10.1038/nature10230

144. De Stefani D, Rizzuto R, Pozzan T. Enjoy the trip: calcium in mitochondria back and forth. Annu Rev Biochem. (2016) 85:161-92. doi: 10.1146/annurev-biochem-060614-034216

145. Ackema KB, Hench J, Bockler S, Wang SC, Sauder U, Mergentaler H, et al. The small GTPase Arf1 modulates mitochondrial morphology and function. EMBO J. (2014) 33:2659-75. doi: 10.15252/embj.201489039

146. Ackema KB, Prescianotto-Baschong C, Hench J, Wang SC, Chia ZH, Mergentaler H, et al. Sar1, a novel regulator of ER-mitochondrial contact sites. PLoS ONE. (2016) 11:e0154280. doi: 10.1371/journal.pone.0154280

147. Walch L, Pellier E, Leng W, Lakisic G, Gautreau A, Contremoulins V, et al. GBF1 and Arf1 interact with Miro and regulate mitochondrial positioning within cells. Sci Rep. (2018) 8:17121. doi: 10.1038/s41598-018-35190-0

148. Sack MN. Mitochondrial fidelity and metabolic agility control immune cell fate and function. J Clin Investig. (2018) 128:3651-61. doi: 10.1172/JCI120845

149. Rizzuto R, Pozzan T. Microdomains of intracellular $\mathrm{Ca}^{2+}$ : molecular determinants and functional consequences. Physiol Rev. (2006) 86:369-408. doi: 10.1152/physrev.00004.2005

150. Antoine JC, Jouanne C. Multiple effects of the phenylhydrazone derivative FCCP on the secretory pathway in rat plasma cells. Eur J Biol. (1986) 42:6873.

151. Argon Y, Burkhardt JK, Leeds JM, Milstein C. Two steps in the intracellular transport of IgD are sensitive to energy depletion. J Immunol. (1989) 142:554-61.

152. Burkhardt JK, Argon Y. Intracellular transport of the glycoprotein of VSV is inhibited by CCCP at a late stage of post-translational processing. J Cell Sci. (1989) 92(Pt 4):633-42.

153. Klein MC, Zimmermann K, Schorr S, Landini M, Klemens PAW, Altensell J, et al. AXER is an ATP/ADP exchanger in the membrane of the endoplasmic 
reticulum. Nat Commun. (2018) 9:3489. doi: 10.1038/s41467-018-0 6003-9

154. Yong J, Bischof H, Burgstaller S, Siirin M, Murphy A, Malli R, et al. Mitochondria supply ATP to the ER through a mechanism antagonized by cytosolic $\mathrm{Ca}^{2+}$. eLife. (2019) 8:e49682. doi: 10.7554/eLife.49682

155. Vishnu N, Jadoon Khan M, Karsten F, Groschner LN, Waldeck-Weiermair $\mathrm{M}$, Rost R, et al. ATP increases within the lumen of the endoplasmic reticulum upon intracellular $\mathrm{Ca}^{2+}$ release. Mol Biol Cell. (2014) 25:368-79. doi: 10.1091/mbc.e13-07-0433

156. Sheng ZH, Cai Q. Mitochondrial transport in neurons: impact on synaptic homeostasis and neurodegeneration. Nat Rev Neurosci. (2012) 13:77-93. doi: $10.1038 / \mathrm{nrn} 3156$

157. Vaccaro V, Devine MJ, Higgs NF, Kittler JT. Mirol-dependent mitochondrial positioning drives the rescaling of presynaptic $\mathrm{Ca}^{2+}$ signals during homeostatic plasticity. EMBO Rep. (2017) 18:231-40. doi: $10.15252 / \mathrm{embr} .201642710$

158. Prakriya M, Lewis RS. Store-operated calcium channels. Physiol Rev. (2015) 95:1383-436. doi: 10.1152/physrev.00020.2014

159. Catterall WA. Voltage-gated calcium channels. Cold Spring Harbor Perspect Biol. (2011) 3:a003947. doi: 10.1101/cshperspect.a003947

160. Vos M, Lauwers E, Verstreken P. Synaptic mitochondria in synaptic transmission and organization of vesicle pools in health and disease. Front Synaptic Neurosci. (2010) 2:139. doi: 10.3389/fnsyn.2010.00139

161. Griesche N, Sanchez G, Hermans C, Idevall-Hagren O. Cortical mitochondria regulate insulin secretion by local $\mathrm{Ca}(2+)$ buffering in rodent beta cells. J Cell Sci. (2019) 132:jcs228544. doi: 10.1242/jcs.228544

162. Quintana A, Schwarz EC, Schwindling C, Lipp P, Kaestner L, Hoth M. Sustained activity of calcium release-activated calcium channels requires translocation of mitochondria to the plasma membrane. J Biol Chem. (2006) 281:40302-9. doi: 10.1074/jbc.M607896200

163. Hoth M, Button DC, Lewis RS. Mitochondrial control of calciumchannel gating: a mechanism for sustained signaling and transcriptional activation in T lymphocytes. Proc Natl Acad Sci USA. (2000) 97:10607-12. doi: 10.1073/pnas.180143997

164. Bezprozvanny I, Watras J, Ehrlich BE. Bell-shaped calcium-response curves of Ins(1,4,5)P3- and calcium-gated channels from endoplasmic reticulum of cerebellum. Nature. (1991) 351:751-4. doi: 10.1038/351751a0

165. Yang Y, Wang H, Kouadir M, Song H, Shi F. Recent advances in the mechanisms of NLRP3 inflammasome activation and its inhibitors. Cell Death Dis. (2019) 10:128. doi: 10.1038/s41419-019-1413-8

166. Park S, Juliana C, Hong S, Datta P, Hwang I, Fernandes-Alnemri T, et al. The mitochondrial antiviral protein MAVS associates with NLRP3 and regulates its inflammasome activity. J Immunol. (2013) 191:4358-66. doi: 10.4049/jimmunol.1301170

167. Ichinohe $\mathrm{T}$, Yamazaki $\mathrm{T}$, Koshiba $\mathrm{T}$, Yanagi Y. Mitochondrial protein mitofusin 2 is required for NLRP3 inflammasome activation after RNA virus infection. Proc Natl Acad Sci USA. (2013) 110:17963-8. doi: 10.1073/pnas.1312571110

168. Misawa T, Takahama M, Kozaki $T$, Lee H, Zou J, Saitoh $T$, et al. Microtubule-driven spatial arrangement of mitochondria promotes activation of the NLRP3 inflammasome. Nat Immunol. (2013) 14:454-60. doi: $10.1038 /$ ni. 2550

169. Boland BB, Rhodes CJ, Grimsby JS. The dynamic plasticity of insulin production in beta-cells. Mol Metab. (2017) 6:958-73. doi: 10.1016/j.molmet.2017.04.010

170. Jitrapakdee S, Wutthisathapornchai A, Wallace JC, MacDonald MJ. Regulation of insulin secretion: role of mitochondrial signalling. Diabetologia. (2010) 53:1019-32. doi: 10.1007/s00125-010-1685-0

171. Jesinkey SR, Madiraju AK, Alves TC, Yarborough OH, Cardone RL, Zhao X, et al. Mitochondrial GTP links nutrient sensing to beta cell health, mitochondrial morphology, and insulin secretion independent of oxphos. Cell Rep. (2019) 28:759-72 e10. doi: 10.1016/j.celrep.2019.06.058

172. Stark R, Pasquel F, Turcu A, Pongratz RL, Roden M, Cline GW, et al. Phosphoenolpyruvate cycling via mitochondrial phosphoenolpyruvate carboxykinase links anaplerosis and mitochondrial GTP with insulin secretion. J Biol Chem. (2009) 284:26578-90. doi: 10.1074/jbc.M109.011775
173. Kennedy ED, Maechler P, Wollheim CB. Effects of depletion of mitochondrial DNA in metabolism secretion coupling in INS-1 cells. Diabetes. (1998) 47:374-80. doi: 10.2337/diabetes.47.3.374

174. Wu JJ, Quijano C, Chen E, Liu H, Cao L, Fergusson MM, et al. Mitochondrial dysfunction and oxidative stress mediate the physiological impairment induced by the disruption of autophagy. Aging. (2009) 1:425-37. doi: 10.18632/aging. 100038

175. Alam MR, Groschner LN, Parichatikanond W, Kuo L, Bondarenko AI, Rost R, et al. Mitochondrial $\mathrm{Ca}^{2+}$ uptake 1 (MICU1) and mitochondrial $\mathrm{Ca}^{2+}$ uniporter (MCU) contribute to metabolism-secretion coupling in clonal pancreatic beta-cells. J Biol Chem. (2012) 287:34445-54. doi: 10.1074/jbc.M112.392084

176. Molina AJ, Wikstrom JD, Stiles L, Las G, Mohamed H, Elorza A, et al. Mitochondrial networking protects beta-cells from nutrient-induced apoptosis. Diabetes. (2009) 58:2303-15. doi: 10.2337/db07-1781

177. Park KS, Wiederkehr A, Kirkpatrick C, Mattenberger Y, Martinou JC, Marchetti P, et al. Selective actions of mitochondrial fission/fusion genes on metabolism-secretion coupling in insulin-releasing cells. J Biol Chem. (2008) 283:33347-56. doi: 10.1074/jbc.M806251200

178. Twig G, Elorza A, Molina AJ, Mohamed H, Wikstrom JD, Walzer G, et al. Fission and selective fusion govern mitochondrial segregation and elimination by autophagy. EMBO J. (2008) 27:433-46. doi: 10.1038/sj.emboj.7601963

179. Kabra UD, Pfuhlmann K, Migliorini A, Keipert S, Lamp D, Korsgren $\mathrm{O}$, et al. Direct substrate delivery into mitochondrial fission-deficient pancreatic islets rescues insulin secretion. Diabetes. (2017) 66:1247-57. doi: $10.2337 / \mathrm{db} 16-1088$

180. American Diabetes A. Diagnosis and classification of diabetes mellitus. Diabetes Care. (2008) 31(Suppl 1):S55-60. doi: 10.2337/dc08-S055

181. DeFronzo RA, Ferrannini E, Groop L, Henry RR, Herman WH, Holst JJ, et al. Type 2 diabetes mellitus. Nat Rev Dis Primers. (2015) 1:15019. doi: $10.1038 /$ nrdp.2015.19

182. Ballinger SW, Shoffner JM, Hedaya EV, Trounce I, Polak MA, Koontz DA, et al. Maternally transmitted diabetes and deafness associated with a $10.4 \mathrm{~kb}$ mitochondrial DNA deletion. Nat Genet. (1992) 1:11-5. doi: $10.1038 /$ ng0492-11

183. van den Ouweland JM, Lemkes HH, Ruitenbeek W, Sandkuijl LA, de Vijlder MF, Struyvenberg PA, et al. Mutation in mitochondrial tRNA(Leu)(UUR) gene in a large pedigree with maternally transmitted type II diabetes mellitus and deafness. Nat Genet. (1992) 1:368-71. doi: 10.1038/ng0892-368

184. Li K, Wu L, Liu J, Lin W, Qi Q, Zhao T. Maternally inherited diabetes mellitus associated with a novel $\mathrm{m} .15897 \mathrm{G}>\mathrm{A}$ mutation in mitochondrial tRNA(Thr) gene. J Diabetes Res. (2020) 2020:2057187. doi: 10.1155/2020/2057187

185. Maassen JA, 'T Hart LM, Van Essen E, Heine RJ, Nijpels G, Jahangir Tafrechi RS, et al. Mitochondrial diabetes: molecular mechanisms and clinical presentation. Diabetes. (2004) 53(Suppl 1):S103-9. doi: 10.2337/diabetes.53.2007.S103

186. Suzuki Y, Iizuka T, Kobayashi T, Nishikawa T, Atsumi Y, Kadowaki T, et al. Diabetes mellitus associated with the 3243 mitochondrial tRNA(Leu)(UUR) mutation: insulin secretion and sensitivity. Metabolism. (1997) 46:1019-23. doi: 10.1016/S0026-0495(97)90272-9

187. Brandle M, Lehmann R, Maly FE, Schmid C, Spinas GA. Diminished insulin secretory response to glucose but normal insulin and glucagon secretory responses to arginine in a family with maternally inherited diabetes and deafness caused by mitochondrial tRNA(LEU(UUR)) gene mutation. Diabetes Care. (2001) 24:1253-8. doi: 10.2337/diacare.24.7.1253

188. Gebhart SS, Shoffner JM, Koontz D, Kaufman A, Wallace D. Insulin resistance associated with maternally inherited diabetes and deafness. Metabolism. (1996) 45:526-31. doi: 10.1016/S0026-0495(96)90231-0

189. Hou J, Li Z, Zhong W, Hao Q, Lei L, Wang L, et al. Temporal transcriptomic and proteomic landscapes of deteriorating pancreatic islets in type 2 diabetic rats. Diabetes. (2017) 66:2188-200. doi: 10.2337/db16-1305

190. Anello M, Lupi R, Spampinato D, Piro S, Masini M, Boggi U, et al. Functional and morphological alterations of mitochondria in pancreatic beta cells from type 2 diabetic patients. Diabetologia. (2005) 48:282-9. doi: $10.1007 / \mathrm{s} 00125-004-1627-9$ 
191. Del Guerra S, Lupi R, Marselli L, Masini M, Bugliani M, Sbrana S, et al. Functional and molecular defects of pancreatic islets in human type 2 diabetes. Diabetes. (2005) 54:727-35. doi: 10.2337/diabetes.54.3.727

192. Fernandez-Alvarez J, Conget I, Rasschaert J, Sener A, Gomis R, Malaisse WJ. Enzymatic, metabolic and secretory patterns in human islets of type 2 (non-insulin-dependent) diabetic patients. Diabetologia. (1994) 37:177-81. doi: $10.1007 / \mathrm{s} 001250050090$

193. Chan CB, De Leo D, Joseph JW, McQuaid TS, Ha XF, Xu F, et al. Increased uncoupling protein-2 levels in beta-cells are associated with impaired glucose-stimulated insulin secretion: mechanism of action. Diabetes. (2001) 50:1302-10. doi: 10.2337/diabetes.50.6.1302

194. Zhang CY, Baffy G, Perret P, Krauss S, Peroni O, Grujic D, et al. Uncoupling protein-2 negatively regulates insulin secretion and is a major link between obesity, beta cell dysfunction, and type 2 diabetes. Cell. (2001) 105:745-55. doi: 10.1016/S0092-8674(01)00378-6

195. Liotta A, Rosner J, Huchzermeyer C, Wojtowicz A, Kann O, Schmitz $\mathrm{D}$, et al. Energy demand of synaptic transmission at the hippocampal Schaffer-collateral synapse. J Cereb Blood Flow Metab. (2012) 32:2076-83. doi: $10.1038 /$ jcbfm.2012.116

196. Verstreken P, Ly CV, Venken KJ, Koh TW, Zhou Y, Bellen HJ. Synaptic mitochondria are critical for mobilization of reserve pool vesicles at Drosophila neuromuscular junctions. Neuron. (2005) 47:365-78. doi: 10.1016/j.neuron.2005.06.018

197. Harris JJ, Jolivet R, Attwell D. Synaptic energy use and supply. Neuron. (2012) 75:762-77. doi: 10.1016/j.neuron.2012.08.019

198. Mattson MP, Gleichmann M, Cheng A. Mitochondria in neuroplasticity and neurological disorders. Neuron. (2008) 60:748-66. doi: 10.1016/j.neuron.2008.10.010

199. Goedert M, Spillantini MG. A century of Alzheimer's disease. Science. (2006) 314:777-81. doi: 10.1126/science. 1132814

200. Mosconi L. Brain glucose metabolism in the early and specific diagnosis of Alzheimer's disease. FDG-PET studies in MCI and AD. Eur J Nucl Med Mol Imaging. (2005) 32:486-510. doi: 10.1007/s00259-005-1762-7

201. Mosconi L, De Santi S, Li J, Tsui WH, Li Y, Boppana M, et al. Hippocampal hypometabolism predicts cognitive decline from normal aging. Neurobiol Aging. (2008) 29:676-92. doi: 10.1016/j.neurobiolaging.2006.12.008

202. Hirai K, Aliev G, Nunomura A, Fujioka H, Russell RL, Atwood CS, et al. Mitochondrial abnormalities in Alzheimer's disease. J Neurosci. (2001) 21:3017-23. doi: 10.1523/JNEUROSCI.21-09-03017.2001

203. Silva DF, Selfridge JE, Lu J, E L, Cardoso SM, Swerdlow RH. Mitochondrial abnormalities in Alzheimer's disease: possible targets for therapeutic intervention. Adv Pharmacol. (2012) 64:83-126. doi: 10.1016/B978-0-12-394816-8.00003-9

204. Gibson GE, Sheu KF, Blass JP. Abnormalities of mitochondrial enzymes in Alzheimer disease. J Neural Trans. (1998) 105:855-70. doi: 10.1007/s007020050099

205. Maurer I, Zierz S, Moller HJ. A selective defect of cytochrome c oxidase is present in brain of Alzheimer disease patients. Neurobiol Aging. (2000) 21:455-62. doi: 10.1016/S0197-4580(00)00112-3

206. Yao J, Irwin RW, Zhao L, Nilsen J, Hamilton RT, Brinton RD. Mitochondrial bioenergetic deficit precedes Alzheimer's pathology in female mouse model of Alzheimer's disease. Proc Natl Acad Sci USA. (2009) 106:14670-5. doi: 10.1073/pnas.0903563106

207. Martino Adami PV, Galeano P, Wallinger ML, Quijano C, Rabossi A, Pagano ES, et al. Worsening of memory deficit induced by energy-dense diet in a rat model of early-Alzheimer's disease is associated to neurotoxic Abeta species and independent of neuroinflammation. Biochim Biophys Acta Mol Basis Dis. (2017) 1863:731-43. doi: 10.1016/j.bbadis.2016.12.014

208. Martino Adami PV, Quijano C, Magnani N, Galeano P, Evelson P, Cassina A, et al. Synaptosomal bioenergetic defects are associated with cognitive impairment in a transgenic rat model of early Alzheimer's disease. J Cereb Blood Flow Metab. (2017) 37:69-84. doi: 10.1177/0271678X156 15132

209. Calkins MJ, Manczak M, Mao P, Shirendeb U, Reddy PH. Impaired mitochondrial biogenesis, defective axonal transport of mitochondria, abnormal mitochondrial dynamics and synaptic degeneration in a mouse model of Alzheimer's disease. Hum Mol Genet. (2011) 20:4515-29. doi: $10.1093 / \mathrm{hmg} / \mathrm{ddr} 381$
210. Zhao XL, Wang WA, Tan JX, Huang JK, Zhang X, Zhang BZ, et al. Expression of beta-amyloid induced age-dependent presynaptic and axonal changes in Drosophila. J Neurosci. (2010) 30:1512-22. doi: 10.1523/JNEUROSCI.3699-09.2010

211. Manczak M, Anekonda TS, Henson E, Park BS, Quinn J, Reddy PH Mitochondria are a direct site of A beta accumulation in Alzheimer's disease neurons: implications for free radical generation and oxidative damage in disease progression. Hum Mol Genet. (2006) 15:1437-49. doi: 10.1093/hmg/ddl066

212. Veereshwarayya V, Kumar P, Rosen KM, Mestril R, Querfurth HW. Differential effects of mitochondrial heat shock protein 60 and related molecular chaperones to prevent intracellular beta-amyloid-induced inhibition of complex IV and limit apoptosis. J Biol Chem. (2006) 281:29468-78. doi: 10.1074/jbc.M602533200

213. Joshi AU, Saw NL, Shamloo M, Mochly-Rosen D. Drp1/Fis1 interaction mediates mitochondrial dysfunction, bioenergetic failure and cognitive decline in Alzheimer's disease. Oncotarget. (2018) 9:6128-43. doi: 10.18632/oncotarget. 23640

214. Wang X, Su B, Siedlak SL, Moreira PI, Fujioka H, Wang Y, et al. Amyloid-beta overproduction causes abnormal mitochondrial dynamics via differential modulation of mitochondrial fission/fusion proteins. Proc Natl Acad Sci USA. (2008) 105:19318-23. doi: 10.1073/pnas.0804871105

215. Cai Q, Tammineni P. Mitochondrial aspects of synaptic dysfunction in Alzheimer's disease. J Alzheimer's Dis. (2017) 57:1087-103. doi: 10.3233/JAD-160726

216. Rao KN, Brown MA. Mast cells: multifaceted immune cells with diverse roles in health and disease. Ann NY Acad Sci. (2008) 1143:83-104. doi: 10.1196/annals.1443.023

217. Metz M, Maurer M. Mast cells-key effector cells in immune responses. Trends Immunol. (2007) 28:234-41. doi: 10.1016/j.it.2007.03.003

218. Douglas WW, Kagayama M. Calcium and stimulus-secretion coupling in the mast cell: stimulant and inhibitory effects of calcium-rich media on exocytosis. J Physiol. (1977) 270:691-703. doi: 10.1113/jphysiol.1977.sp011976

219. Zhang B, Asadi S, Weng Z, Sismanopoulos N, Theoharides TC. Stimulated human mast cells secrete mitochondrial components that have autocrine and paracrine inflammatory actions. PLoS ONE. (2012) 7:e49767. doi: 10.1371/journal.pone.0049767

220. Campisi J. Aging, cellular senescence, and cancer. Annu Rev Physiol. (2013) 75:685-705. doi: 10.1146/annurev-physiol-030212-183653

221. Chen QM, Tu VC, Liu J. Measurements of hydrogen peroxide induced premature senescence: senescence-associated beta-galactosidase and DNA synthesis index in human diploid fibroblasts with down-regulated p53 or Rb. Biogerontology. (2000) 1:335-9. doi: 10.1023/a:1026590501344

222. Hayflick L. The limited in vitro lifetime of human diploid cell strains. Exp Cell Res. (1965) 37:614-36. doi: 10.1016/0014-4827(65)90211-9

223. Serrano M, Lin AW, McCurrach ME, Beach D, Lowe SW. Oncogenic ras provokes premature cell senescence associated with accumulation of p53 and p16INK4a. Cell. (1997) 88:593-602. doi: 10.1016/S0092-8674(00)81902-9

224. Coppe JP, Patil CK, Rodier F, Sun Y, Munoz DP, Goldstein J, et al. Senescenceassociated secretory phenotypes reveal cell-nonautonomous functions of oncogenic RAS and the p53 tumor suppressor. PLoS Biol. (2008) 6:2853-68. doi: 10.1371/journal.pbio.0060301

225. Rodier F, Campisi J. Four faces of cellular senescence. J Cell Biol. (2011) 192:547-56. doi: 10.1083/jcb.201009094

226. Acosta JC, O'Loghlen A, Banito A, Guijarro MV, Augert A, Raguz S, et al. Chemokine signaling via the CXCR2 receptor reinforces senescence. Cell. (2008) 133:1006-18. doi: 10.1016/j.cell.2008.03.038

227. Kuilman T, Michaloglou C, Vredeveld LC, Douma S, van Doorn $\mathrm{R}$, Desmet CJ, et al. Oncogene-induced senescence relayed by an interleukin-dependent inflammatory network. Cell. (2008) 133:1019-31. doi: 10.1016/j.cell.2008.03.039

228. Kuilman T, Peeper DS. Senescence-messaging secretome: SMS-ing cellular stress. Nat Rev Cancer. (2009) 9:81-94. doi: 10.1038/nrc2560

229. Munoz-Espin D, Serrano M. Cellular senescence: from physiology to pathology. Nat Rev Mol Cell Biol. (2014) 15:482-96. doi: 10.1038/nrm3823

230. Sharpless NE, Sherr CJ. Forging a signature of in vivo senescence. Nat Rev Cancer. (2015) 15:397-408. doi: 10.1038/nrc3960 
231. Ito $\mathrm{Y}$, Hoare M, Narita M. Spatial and temporal control of senescence. Trends Cell Biol. (2017) 27:820-32. doi: 10.1016/j.tcb.2017. 07.004

232. Dorr JR, Yu Y, Milanovic M, Beuster G, Zasada C, Dabritz JH, et al. Synthetic lethal metabolic targeting of cellular senescence in cancer therapy. Nature. (2013) 501:421-5. doi: 10.1038/nature12437

233. Perez-Mancera PA, Young AR, Narita M. Inside and out: the activities of senescence in cancer. Nat Rev Cancer. (2014) 14:547-58. doi: $10.1038 / \mathrm{nrc} 3773$

234. Moiseeva O, Bourdeau V, Roux A, Deschenes-Simard X, Ferbeyre G. Mitochondrial dysfunction contributes to oncogene-induced senescence. Mol Cell Biol. (2009) 29:4495-507. doi: 10.1128/MCB.01868-08

235. Kaplon J, Zheng L, Meissl K, Chaneton B, Selivanov VA, Mackay G, et al. A key role for mitochondrial gatekeeper pyruvate dehydrogenase in oncogeneinduced senescence. Nature. (2013) 498:109-12. doi: 10.1038/nature12154

236. Hutter E, Renner K, Pfister G, Stockl P, Jansen-Durr P, Gnaiger E. Senescence-associated changes in respiration and oxidative phosphorylation in primary human fibroblasts. Biochem J. (2004) 380(Pt 3):919-28. doi: 10.1042/bj20040095

237. Zwerschke W, Mazurek S, Stockl P, Hutter E, Eigenbrodt E, JansenDurr P. Metabolic analysis of senescent human fibroblasts reveals a role for AMP in cellular senescence. Biochem J. (2003) 376(Pt 2):403-11. doi: 10.1042/bj20030816

238. Ahn BH, Kim HS, Song S, Lee IH, Liu J, Vassilopoulos A, et al. A role for the mitochondrial deacetylase Sirt3 in regulating energy homeostasis. Proc Natl Acad Sci USA. (2008) 105:14447-52. doi: 10.1073/pnas.0803790105

239. Lee AC, Fenster BE, Ito H, Takeda K, Bae NS, Hirai $\mathrm{T}$, et al. Ras proteins induce senescence by altering the intracellular levels of reactive oxygen species. J Biol Chem. (1999) 274:7936-40. doi: 10.1074/jbc.274.1 2.7936

240. Passos JF, Saretzki G, Ahmed S, Nelson G, Richter T, Peters H, et al. Mitochondrial dysfunction accounts for the stochastic heterogeneity in telomere-dependent senescence. PLoS Biol. (2007) 5:e110. doi: 10.1371/journal.pbio.0050110

241. Sakai Y, Yamamori T, Yoshikawa Y, Bo T, Suzuki M, Yamamoto K, et al. NADPH oxidase 4 mediates ROS production in radiation-induced senescent cells and promotes migration of inflammatory cells. Free Radical Res. (2018) 52:92-102. doi: 10.1080/10715762.2017.1416112
242. Weyemi U, Lagente-Chevallier O, Boufraqech M, Prenois F, Courtin F, Caillou B, et al. ROS-generating NADPH oxidase NOX4 is a critical mediator in oncogenic H-Ras-induced DNA damage and subsequent senescence. Oncogene. (2012) 31:1117-29. doi: 10.1038/onc.2011.327

243. Nelson G, Kucheryavenko O, Wordsworth J, von Zglinicki T. The senescent bystander effect is caused by ROS-activated NF-кB signalling. Mech Ageing Dev. (2018) 170:30-6. doi: 10.1016/j.mad.2017.08.005

244. Passos JF, Nelson G, Wang C, Richter T, Simillion C, Proctor CJ, et al. Feedback between p21 and reactive oxygen production is necessary for cell senescence. Mol Syst Biol. (2010) 6:347. doi: 10.1038/msb.2010.5

245. Rodier F, Coppe JP, Patil CK, Hoeijmakers WA, Munoz DP, Raza SR, et al. Persistent DNA damage signalling triggers senescence-associated inflammatory cytokine secretion. Nat Cell Biol. (2009) 11:973-9. doi: $10.1038 /$ ncb1909

246. Rodier F, Munoz DP, Teachenor R, Chu V, Le O, Bhaumik D, et al. DNASCARS: distinct nuclear structures that sustain damage-induced senescence growth arrest and inflammatory cytokine secretion. J Cell Sci. (2011) 124(Pt 1):68-81. doi: $10.1242 /$ jcs.071340

247. Calcinotto A, Kohli J, Zagato E, Pellegrini L, Demaria M, Alimonti A. Cellular senescence: aging, cancer, and injury. Physiol Rev. (2019) 99:104778. doi: 10.1152/physrev.00020.2018

248. Kirkland JL, Tchkonia T. Cellular senescence: a translational perspective. EBioMedicine. (2017) 21:21-8. doi: 10.1016/j.ebiom.2017.04.013

249. Zhu Y, Tchkonia T, Pirtskhalava T, Gower AC, Ding H, Giorgadze N, et al The Achilles' heel of senescent cells: from transcriptome to senolytic drugs. Aging cell. (2015) 14:644-58. doi: 10.1111/acel.12344

Conflict of Interest: The authors declare that the research was conducted in the absence of any commercial or financial relationships that could be construed as a potential conflict of interest.

Copyright (C) 2020 Martínez, Marmisolle, Tarallo and Quijano. This is an open-access article distributed under the terms of the Creative Commons Attribution License (CC $B Y)$. The use, distribution or reproduction in other forums is permitted, provided the original author(s) and the copyright owner(s) are credited and that the original publication in this journal is cited, in accordance with accepted academic practice. No use, distribution or reproduction is permitted which does not comply with these terms. 